Article

\title{
Impacts of Separator Thickness on Temperature Distribution and Power Generation Characteristics of a Single PEMFC Operated at Higher Temperature of 363 and $373 \mathrm{~K}$
}

\author{
Akira Nishimura ${ }^{1, *(D)}$, Yuya Kojima ${ }^{1}$, Syogo Ito ${ }^{1}$ and Eric $\mathrm{Hu}^{2}$ (D) \\ 1 Division of Mechanical Engineering, Graduate School of Engineering, Mie University, 1577 Kurimamachiya-cho, \\ Tsu 514-8507, Japan; 420m118@m.mie-u.ac.jp (Y.K.); 418110@m.mie-u.ac.jp (S.I.) \\ 2 School of Mechanical Engineering, The University of Adelaide, Adelaide, SA 5005, Australia; \\ eric.hu@adelaide.edu.au \\ * Correspondence: nisimura@mach.mie-u.ac.jp; Tel.: +81-59-231-9747
}

\section{check for}

updates

Citation: Nishimura, A.; Kojima, Y.; Ito, S.; Hu, E. Impacts of Separator

Thickness on Temperature

Distribution and Power Generation Characteristics of a Single PEMFC

Operated at Higher Temperature of

363 and 373 K. Energies 2022, 15, 1558

https://doi.org/10.3390/en15041558

Academic Editors: D.S. Falcão,

Alexandra M.F.R. Pinto, Rui Ferreira

and Attilio Converti

Received: 20 January 2022

Accepted: 16 February 2022

Published: 20 February 2022

Publisher's Note: MDPI stays neutral with regard to jurisdictional claims in published maps and institutional affiliations.

Copyright: (c) 2022 by the authors. Licensee MDPI, Basel, Switzerland. This article is an open access article distributed under the terms and conditions of the Creative Commons Attribution (CC BY) license (https:/ / creativecommons.org/licenses/by/ $4.0 /)$.

\begin{abstract}
The aim of this study is to investigate the effects of the separator thickness on not only the heat and mass transfer characteristics, but also the power generation characteristics of a polymer electrolyte membrane fuel cell (PEMFC) with a thin polymer electrolyte membrane (PEM) and thin gas diffusion layer (GDL) operated at higher temperatures of 363 and $373 \mathrm{~K}$. The in-plane temperature distributions on the back of the separator at the anode and cathode, which are the opposite sides to the GDL, are measured using a thermograph at various initial cell temperatures $\left(T_{\text {init }}\right)$, relative humidity (RH) levels, and supply gas flow rates. The total voltage corresponding to the load current is measured in order to evaluate the performance of the PEMFC. As a result, it is revealed that the effect of the RH on the power generation characteristics is more significant when the separator thickness decreases. It is revealed that the power generation performance obtained at high current densities decreases with the increase in $T_{\text {init }}$ with thinner separator thicknesses. According to the investigation of the in-plane temperature distribution, it is clarified that the temperature decreases at corner positions in the separator with the separator thickness of $2.0 \mathrm{~mm}$, while the temperature gradually increases along with the gas flow with separator thicknesses of $1.5 \mathrm{~mm}$ and $1.0 \mathrm{~mm}$.
\end{abstract}

Keywords: PEMFC; high-temperature operation; thickness of separator; temperature distribution; power generation performance

\section{Introduction}

We know from the Japanese New Energy and Industry Technology Development Organization (NEDO) road map 2017 [1] that the operation temperature range of polymer electrolyte membrane fuel cell (PEMFC) systems is $363 \mathrm{~K}$ to $373 \mathrm{~K}$, which are relatively higher temperatures than the present operation temperature for stationary and mobility applications. If PEMFC systems were operated in the temperature range of $363 \mathrm{~K}$ to $373 \mathrm{~K}$, this would have the following advantages: (1) improvement of the electrochemical kinetics at both anode and cathode sides; (2) reduction in the cooling system for automobile applications because of the increase in temperature difference between the PEMFC stack and coolant; (3) durability improvements for $\mathrm{CO}$ contained in $\mathrm{H}_{2}$ reformed from hydrocarbon [2]. However, the operation temperatures of current PEMFC systems using Nafion membranes are usually between 333 and 353 K [3-5]. The following issues must be considered when PEMFC systems are operated at relatively higher temperatures than usual: (1) degradation of the PEM; (2) erosion of electrodes; (3) uneven distributions of the gas concentration, temperature and current in PEMFCs. These challenging issues should be resolved [6]. Moreover, we can say that the temperature distribution influences the phase change of $\mathrm{H}_{2} \mathrm{O}$, which affects the performance of the polymer electrolyte membrane (PEM) and fuel and oxidant flows in the gas diffusion layer (GDL) and the catalyst layer 
when the PEMFC system is operated at a higher temperatures, such as $363 \mathrm{~K}$ and $373 \mathrm{~K}$. Consequently, it is necessary to clarify the temperature distribution in PEMFC cells to promote power generation and achieve longer operation times.

The high-temperature PEMFC (HTPEMFC) characteristics have been investigated recently at temperatures over $373 \mathrm{~K}$ [7-20]. However, many studies have focused on the R\&D of new materials, e.g., membranes and catalysts [7-13]. Polybenzimidazole-graphene oxide composite membranes were developed and the maximum power of $546 \mathrm{~W}$ (voltage of $5.2 \mathrm{~V}$ at $105 \mathrm{~A}$ ) was achieved using 12 cell stacks [7]. New polymers (poly-phenylene oxide) composed of a phosphate group, including methyl phosphonic acid and 6-oxohexyl phosphonic acid, showing good proton activities, were developed as ionomers and binders in order to form an electrode [8]. The electrode containing a surfactant was been fabricated in order to improve the dispersion of the polytetrafluoroethylene binder and in order to enhance the reproducibility during manufacturing of the electrode, which showed a relatively high voltage of $0.65 \mathrm{~V}$ at the current density of $0.2 \mathrm{~A} / \mathrm{cm}^{2}$ [9]. The physical structure and composition of the catalyst layer were investigated, showing that a proper combination of $10 \mathrm{wt} \% \mathrm{Pt} / \mathrm{C}$ with polytetrafluoroethylene (PTFE) ionomer can gain $0.62 \mathrm{~A} / \mathrm{cm}^{2}$ output at $0.3067 \mathrm{~V}$ [10]. It has been reported that the proton conductivity of amino-modified polybenzimidazoles with ethyl phosphonic acid groups is $0.0062 \mathrm{~S} / \mathrm{cm}^{2}$ at $443 \mathrm{~K}$ [11]. An accelerated stress test was conducted for PEM composed of polybenzimidazole $/ \mathrm{H}_{3} \mathrm{PO}_{4}$, which showed $20 \%$ mass loss of the electrodes after 1562 cycles (3124 start and shutdown steps) [12]. The review reported a comparison of performances among PEMs made of polybenzimidazoles, sulphonated polyether ether ketones and pyridine-based materials operated at high temperatures above $373 \mathrm{~K}$, concluding that it is necessary to perform careful multi-physics modeling of PEM in order to improve $\mathrm{H}_{2} \mathrm{O}$ and thermal management [13]. A numerical study analyzed the distribution of the current density, $\mathrm{O}_{2}$ and $\mathrm{H}_{2} \mathrm{O}$ concentrations when the assembly pressure was changed [14]. The power generation characteristics were investigated using polarization and power curves and by changing the membrane thickness [15]. The other numerical studies reported on the electrolyte potential distribution calculated via numerical simulations using 2D and 3D models [16] and mathematical models to predict the deterioration of membranes and catalysts [17]. Other experimental studies have investigated the impact of a stainless bipolar plate coated with $\mathrm{CrN} / \mathrm{Cr}$ on the power generation performance [18], the impacts of flow rate of the supply gas and assembly pressure on the power generation characteristics using a stainless separator [19], and the impact of the gas pressure of the supply gas on the power generation characteristics [20]. Other studies $[6,21]$ have investigated the temperature distribution in single-PEMFC systems, which are operated at high temperature. The studies conducted by the authors reported on the effects of the thickness of PEM, GDL and MPL on the temperature distribution on the back of the separator and the power generation characteristics at higher temperature such as $363 \mathrm{~K}$ and $373 \mathrm{~K}$, both experimentally and numerically [22-24]. As a result, the combination of thin PEM and thin GDL is suitable for high-temperature operation and uniform in-plane temperature distribution. Regarding the separator, the numerical investigation on the impacts of the cross-sectional area shape of the gas flow channel on the distributions of $\mathrm{H}_{2}$ and $\mathrm{O}_{2}$ concentrations in the flow channel and the distribution of the current density on PEM at $453 \mathrm{~K}$ were reported [25]. In addition, the impacts of the rib and channel sizes of the separator on the power generation characteristics and the mass concentration distributions in HTPEMFC were investigated numerically $[14,26]$, showing that a high current density can be obtained under the channel with a small channel-to-rib ratio, while a high channel-to-rib ratio could cause high current density appearances under the rib [26]. However, the impacts of the separator thickness, which influences the weight, volume and cost of PEMFC stack system, on not only heat and mass transfer phenomena but also power generation characteristics have not been reported yet. It is effective in automobile applications of PEMFC systems to reduce the weight and volume, since the mileage is improved and the space for the driver and passengers in 
the automobile becomes larger. In addition, this is also attractive for the co-generation application of PEMFC systems, since the cost can be reduced.

The purpose of this paper is to understand the effects of the separator thickness on heat and mass transfer characteristics and power generation characteristics of PEMFC systems operated at higher temperatures than usual (e.g., $363 \mathrm{~K}$ or $373 \mathrm{~K}$ ). The temperatures of $363 \mathrm{~K}$ and $373 \mathrm{~K}$ were selected as the target temperatures for PEMFC system application in Japan [1]. In addition, $353 \mathrm{~K}$ was selected as the normal operation temperature to compare the characteristics when operated at the target high temperature. The in-plane temperature distributions on the back of the separator at the anode and cathode, which are the opposite sides to the GDL, were measured using a thermograph at various operation temperatures, relatively humidity $(\mathrm{RH})$ levels, and supply gas flow rates. The total voltage corresponding to the load current generated by the PEMFC was also measured and analyzed.

\section{Experimental System with a Single PEMFC}

\subsection{Experimental Setup and Procedure}

Single cells of PEMFC (MC-25-SC-NH; produced by Reactive Innovations, Westford, MA, USA) and Nafion NRE-211 (produced by DuPont Corp., Tokyo, Japan) with a thickness of $25 \mu \mathrm{m}$ and TGP-H-030 (produced by Toray Corp., Tokyo, Japan) with a thickness of $110 \mu \mathrm{m}$ as PEM and GDL, respectively, were used. These PEM and GDL cells were selected following the results of past studies [22-24]. Regarding the separator size, the thickness of the saddle part and depth of the channel part were changed. We used separator thicknesses of $2.0 \mathrm{~mm}$ (saddle thickness: $1.0 \mathrm{~mm}$, channel height: $1.0 \mathrm{~mm}$ ), $1.5 \mathrm{~mm}$ (saddle thickness: $0.5 \mathrm{~mm}$, channel height: $1.0 \mathrm{~mm}$ ) and $1.0 \mathrm{~mm}$ (saddle height: $0.5 \mathrm{~mm}$, channel height: $0.5 \mathrm{~mm}$ ). In this study, the clamp pressure of the cell was controlled by the torque bolting cell components, which was fixed at $3 \mathrm{~N} \mathrm{~m}$. Under such conditions, gas leakage does not occur and the level of power generation can be maintained. Table 1 shows the specifications of cell components of the single cells of PEFC used in this study. Figure 1 shows the experimental procedure and cell structure used to measure the temperature $[22,23,27,28]$. The current collector and end plate had a hole measuring $50 \mathrm{~mm} \times 50 \mathrm{~mm}$, which was used to measure temperature via thermographs, having the same size as the electrode. The hot water passage plate had a hole measuring $40 \mathrm{~mm} \times 50 \mathrm{~mm}$. The reason why the width of hole used for hot water passage plate was narrower was in order to make the observation window. As a result, gas leakage occurred, since the gas inlet and gas outlet, which were located in the upper right corner and the lower left corner of the separator, respectively, could not be covered by the hot water passage plate well. Therefore, in this study we decided that the width of the hole for the hot water passage plate should be $40 \mathrm{~mm}$, meaning that gas leakage did not occur. Since the hole made for the hot water passage plate was $40 \mathrm{~mm} \times 50 \mathrm{~mm}$, the observation area of the separator for the temperature measurement was also $40 \mathrm{~mm} \times 50 \mathrm{~mm}$.

We measured the in-plane temperature distributions on the back of the separator at the anode and cathode through the hole using a thermograph (Themotracer TH9100WL; produced by Nippon Avionics Co., Ltd., Tokyo, Japan). Figure 1 also shows the space and temperature resolutions. We analyzed the measured temperature data using dedicated software (TH91-702; produced by Nippon Avoinics Co., Ltd., Tokyo, Japan.). Black body tape (HB-250; produced by Optix) with a thickness of $0.1 \mathrm{~mm}$ was fitted on the back of the separator to maintain the measurement accuracy by preventing surface roughness and reflection variations. We measured the emissivity of the black body tape before the temperature measurement. According to the pre-experiment, the impact of the observation window on the power generation performance can be ignored. In this pre-experiment, the initial temperature was set to $343 \mathrm{~K}$, and the RHs of supply gases of the anode and cathode were $80 \% \mathrm{RH}$ with and without a hole for the purpose of temperature measurement observations $[27,28]$. According to this pre-experiment, we confirmed voltage drops caused by observation window at the current (load) density of $0.80 \mathrm{~A} / \mathrm{cm}^{2}$ during anode and 
cathode observation tests of only $4 \%$ and $7 \%$, respectively. Therefore, we ignored the impact of the observation window on the power generation performance.

Table 1. Specifications of cell components of a single PEFC. The separator size was changed as a main parameter in this study.

\begin{tabular}{|c|c|c|}
\hline Components & Size & Information \\
\hline PEM & $50.0 \mathrm{~mm} \times 50.0 \mathrm{~mm} \times 0.025 \mathrm{~mm}$ & $\begin{array}{l}\text { Nafion NRE-211 (manufactured by } \\
\text { DuPont Corp., Tokyo, Japan) }\end{array}$ \\
\hline Catalyst layer & $50.0 \mathrm{~mm} \times 50.0 \mathrm{~mm}($ fitted on PEM$)$ & $\mathrm{Pt} /$ carbon (loading ratio of $\mathrm{Pt}: 20 \mathrm{wt} \%$ ) \\
\hline GDL & $50.0 \mathrm{~mm} \times 50.0 \mathrm{~mm} \times 0.110 \mathrm{~mm}$ & $\begin{array}{l}\text { TGP-H-030 (manufactured by Toray } \\
\text { Corp., Tokyo, Japan) }\end{array}$ \\
\hline Gas separator & $\begin{array}{l}75.4 \mathrm{~mm} \times 75.4 \mathrm{~mm} \times 2.0 \mathrm{~mm} \text { (saddle thickness: } \\
1.0 \mathrm{~mm} \text {, channel height: } 1.0 \mathrm{~mm}), 1.5 \mathrm{~mm} \text { (saddle } \\
\text { thickness: } 0.5 \mathrm{~mm} \text {, channel height: } 1.0 \mathrm{~mm}), 1.0 \\
\text { mm (saddle thickness: } 0.5 \mathrm{~mm} \text {, channel height: } 0.5 \\
\text { mm); } 50.0 \mathrm{~mm} \times 50.0 \mathrm{~mm} \text { (gas supply area) }\end{array}$ & $\begin{array}{l}\text { made from carbon graphite, serpentine } \\
\text { flow channel }\end{array}$ \\
\hline Hot water passage plate & $75.4 \mathrm{~mm} \times 75.4 \mathrm{~mm} \times 2.0 \mathrm{~mm}$ & made from carbon graphite \\
\hline Current collector & $83.3 \mathrm{~mm} \times 83.3 \mathrm{~mm} \times 2.0 \mathrm{~mm}$ & made from copper coated with gold \\
\hline End plate & $110 \mathrm{~mm} \times 110 \mathrm{~mm} \times 12.7 \mathrm{~mm}$ & made from alumina \\
\hline
\end{tabular}

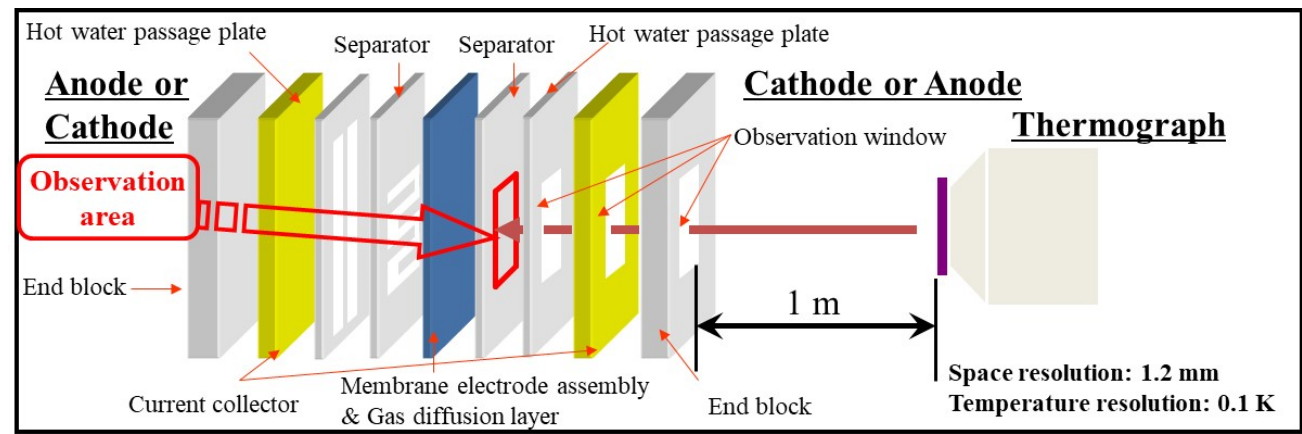

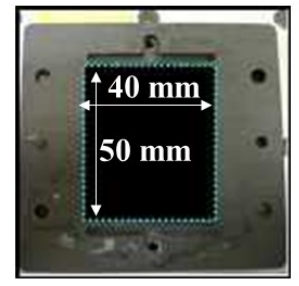

Hot water passage plate (after boring)

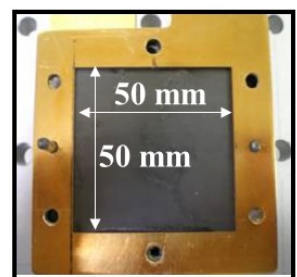

Current collector (after boring)

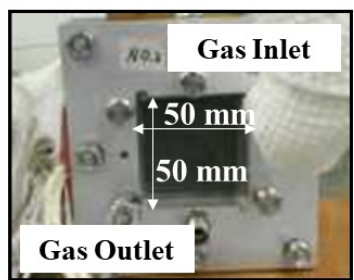

Observation area

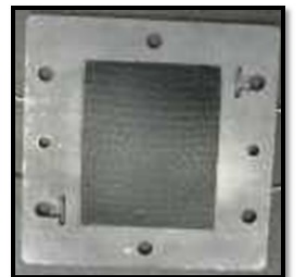

Backside of separator with a black body tape

Figure 1. PEMFC structure used to measure temperature using a thermograph.

The observation window was made by boring a hot water passage plate, current collector and end plate. The in-plane temperature distributions on the back of the separator at the anode and cathode were measured by thermography through the observation window (photos shown in the figure were taken by authors).

All sides of the cell except for the observation window side and opposite side were covered by thermal insulation. We measured the in-plane temperature distribution caused by the reaction heat via a thermograph. The current density was kept at $0.80 \mathrm{~A} / \mathrm{cm}^{2}$, meaning that the temperature of single cell with no heat input from the electric heater could be measured $[27,28]$. The manufacture's descriptions indicate that the thermal conductivities of the PEM, GDL and separator are $0.195,1.7$ and $25 \mathrm{~W} /(\mathrm{M} \cdot \mathrm{K})$, respectively. On the other hand, the thermal conductivities of the hot water passage plate, current collector and end block are 25, 380 and $220 \mathrm{~W} /(\mathrm{M} \cdot \mathrm{K})$, respectively. The thermal conductivities of the hot 
water passage plate, current collector and end block located outside of the separator are higher than those of the PEM, GDL and separator, resulting in the air surrounding the cell having no impact on the temperature distribution [25,27]. A gas leak was detected without a hot water passage plate, meaning that the hot water passage plate with no flowing hot water was installed to prevent the gas leak.

Table 2 lists the power generation conditions. Figure 2 shows the experimental setup. The temperatures of supply gases were controlled by electric heaters to maintain the same temperature as the initial temperature of the cell $\left(T_{\text {init }}\right)$. We controlled the RH for supply gases using humidifiers and dew point meters (MHT337FC; manufactured by VAISALA, Tokyo, Japan). We investigated the RHs of the supply gases as follows: anode at $80 \% \mathrm{RH}$ and cathode at $80 \%$ RH (A80\%RH\&C $80 \%$ RH); anode at $80 \%$ RH and cathode at $40 \% \mathrm{RH}$ (A80\%RH\&C40\%RH); anode at $40 \% \mathrm{RH}$ and cathode at $80 \% \mathrm{RH}(\mathrm{A} 40 \% \mathrm{RH} \& \mathrm{C} 80 \% \mathrm{RH})$; anode at $40 \% \mathrm{RH}$ and cathode at $40 \% \mathrm{RH}$ (A40\%RH\&C40\%RH). It was reported in the Japanese NEDO Road Map 2017 [1] that PEMFC systems must be operated at relatively higher temperature such as $363 \mathrm{~K}$ and $373 \mathrm{~K}$ and low relative humidity levels such as $30 \% \mathrm{RH}$. Therefore, in this study we investigated the possibility of power generation under low relative humidity conditions. Since power generation could not be achieved at $30 \% \mathrm{RH}$ when the initial temperature of the cell was $363 \mathrm{~K}$, we selected $40 \% \mathrm{RH}$ as the lowest relative humidity. In addition, we also selected the relative humidity level of $80 \% \mathrm{RH}$ to investigate the quantitative effect of humidification by comparing the result with that obtained at $40 \% \mathrm{RH}$. Therefore, we considered it unnecessary to investigate the performance at $100 \%$ RH. In this study, we also selected different relative humidity levels between the anode and cathode, since $\mathrm{H}_{2} \mathrm{O}$ transfer promotion between the anode and cathode is expected due to the difference in $\mathrm{H}_{2} \mathrm{O}$ vapor concentration. The flow rates of supply gases were controlled using a mass flow controller. The flow rates of supply gases were changed using stoichiometric ratios (s.r.) of 1.5, 2.0 and 3.0, and pure $\mathrm{H}_{2}$ and pure $\mathrm{O}_{2}$ were applied for the anode and cathode as a fuel and an oxidant, respectively. In addition, the stoichiometric ratios at the anode and cathode were kept the same. Since it has been confirmed that the power generation performance and in-plane temperature distribution are almost the same among various s.r., this study shows the data for an s.r. of 1.5 as representative in this paper. Moreover, we believe that a low gas flow rate is better in order to reduce energy consumption and costs when preheating and supplying the gases in PEMFC systems when power generation is performed well. Therefore, we selected the results with an s.r. of 1.5. The flow rates of supply gases were controlled using the mass flow controller (5850E; produced by Brooks Instruments, Tokyo, Japan). We defined the flow rate of the supply gas with an s.r. of 1.0 using Equation (1):

$$
M_{\mathrm{H} 2}=I / n F
$$

where $M_{\mathrm{H} 2}$ indicates a molar flow rate of $\mathrm{H}_{2}(\mathrm{~mol} / \mathrm{s}), I$ indicates a load current (A), $n$ indicates a valence ion $(=2)$, and $F$ indicates the Faraday constant $(=96,500)(\mathrm{C} / \mathrm{mol}) . M_{\mathrm{H} 2}$ has the same value as the amount of $\mathrm{H}_{2}$ for an s.r. of 1.0. $\mathrm{M}_{\mathrm{O} 2}$ means the molar flow rate of $\mathrm{O}_{2}\left(\mathrm{~mol} / \mathrm{s}\right.$ ) with half of $M_{\mathrm{H} 2}$ (as understood from Equation (2)):

$$
\mathrm{H}_{2}+1 / 2 \mathrm{O}_{2} \rightarrow \mathrm{H}_{2} \mathrm{O}
$$

The load current of a single PEMFC was controlled using the electronic load equipment (PLZ603W; produced by Kikusui Electronics Corp., Yokohama, Japan). The total voltage decided by the load current was measured using the electric load device.

The cell was heated for startup using electric heaters (silicon rubber heater MG; produced using an OM Heater, Nagoya, Japan) installed around the end block of the cell. $\mathrm{H}_{2}$ and $\mathrm{O}_{2}$ were heated up to $T_{\text {init }}$ before they were supplied into the cell during the startup. After the cell temperature reached $T_{\text {init }}$, the power generation of the PEMFC was conducted by changing the load current. The flow rates of supply gases were maintained and the 
temperature distribution was maintained in the steady state for $30 \mathrm{~min}$ by maintaining the constant load current.

Table 2. Power generation conditions. Although the flow rates of supply gases for the anode and cathode were changed via the stoichiometric ratios of 1.5, 2.0 and 3.0, this study shows the results for a stoichiometric ratio of 1.5 .

\begin{tabular}{|c|c|c|}
\hline Initial temperature of cell $\left(T_{\text {init }}\right)[\mathrm{K}]$ & \multicolumn{2}{|c|}{$353,363,373$} \\
\hline Load current $[\mathrm{A}]$ & \multicolumn{2}{|c|}{ 0-20 (0-0.80) or I-V test, } \\
\hline (Current density $\left[\mathrm{A} / \mathrm{cm}^{2}\right]$ ) & \multicolumn{2}{|c|}{$20(0.80)$ for temperature measurement } \\
\hline \multicolumn{3}{|c|}{ Supply gas characterization } \\
\hline & Anode & Cathode \\
\hline Gas type & $\mathrm{H}_{2}$ (purity of $99.995 \mathrm{vol} \%$ ) & $\mathrm{O}_{2}$ (purity of $99.995 \mathrm{vol} \%$ ) \\
\hline Temperature $[\mathrm{K}]$ & $353,363,373$ & $353,363,373$ \\
\hline RH $[\% R H]$ & 40,80 & 40,80 \\
\hline Pressure (absolute) [MPa] & 0.4 & 0.4 \\
\hline Flow rate $[\mathrm{NL} / \mathrm{min}]$ & 0.210 & 0.105 \\
\hline (Stoichiometric ratio $[-]$ ) & $(1.5)$ & (1.5) \\
\hline
\end{tabular}

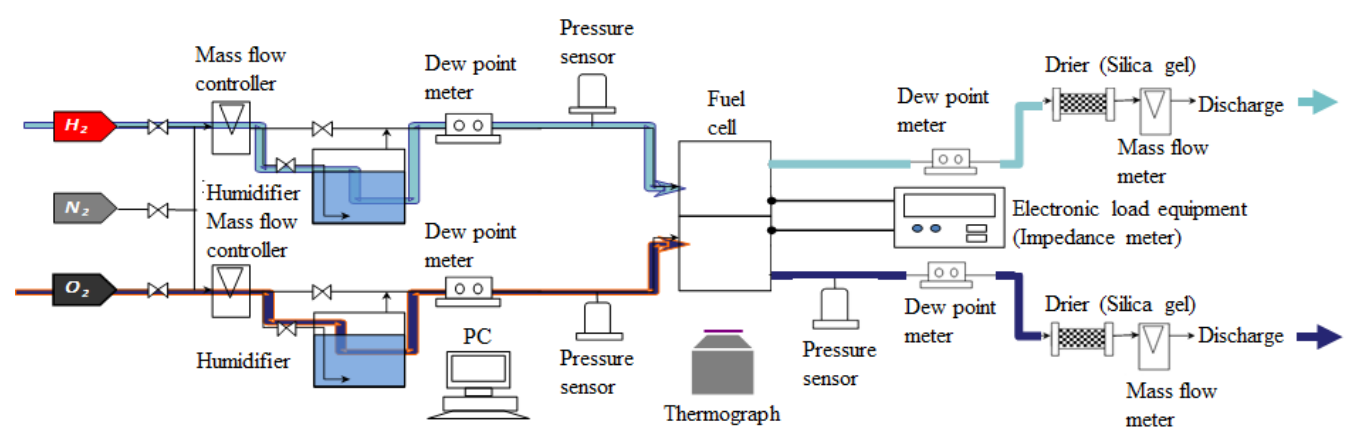

Figure 2. Schematic drawing of the experimental setup. The flow rates of supply gases were controlled using a mass flow controller. The load current of a single PEMFC was controlled via the electronic load equipment.

\subsection{Analysis Procedure for Temperature Images Measured by Thermography}

We obtained temperature images from the thermograph and divided them into segments. It is shown in Figure 3 that the image of the measured temperature is divided into areas measuring $10 \mathrm{~mm} \times 10 \mathrm{~mm}$. There are 20 areas named from A to $\mathrm{T}$, along with the gas flow through the gas channel. We calculated the mean temperature in each area from the temperature image. For areas $\mathrm{A}$ and $\mathrm{T}$, we measured the temperatures without the area where the thermal insulator covering the gas pipe at the inlet and the outlet of cell disturbed the infrared ray in the thermograph.

The temperature difference $T_{\mathrm{i}}-T_{\text {ave }}(\mathrm{K})$ was adopted as the criterion in order to evaluate the in-plane temperature distribution, where $T_{\mathrm{i}}$ indicates the average temperature in the respective area ( $\mathrm{A}$ to $\mathrm{T}$ ) and $T_{\text {ave }}$ indicates the average temperature among all areas from A to $\mathrm{T}$. We defined $T_{\text {ave }}$ as follows:

$$
T_{\text {ave }}=\frac{\sum_{i=A}^{T} T_{\mathrm{i}}}{20}
$$

We also evaluated the temperature distribution via the temperature difference between the maximum temperature $\left(T_{\max }\right)$ and the minimum temperature $\left(T_{\min }\right)$ among the temperatures at locations from $\mathrm{A}$ to $\mathrm{T}$ under each operation condition.

Dedicated software was used to analyze the images of the temperature distribution measured using the thermograph. For the thermograph, the minimum resolution of the temperature and the space used for the measurement were $0.1 \mathrm{~K}$ and $1 \mathrm{~mm}$, respectively. The average temperature in each area was calculated from the temperature image, which 
comprised $29 \times 29$ digital data points. For areas A and T, the digital data points for the area disrupted by the thermal insulator covering the gas pipe at the inlet and the outlet of the cell were removed when we calculated the average temperature, as mentioned above. The temperature difference $T_{\mathrm{i}}-T_{\text {ave }}$ was adopted in order to evaluate the gradient of in-the plane temperature distribution in this study.

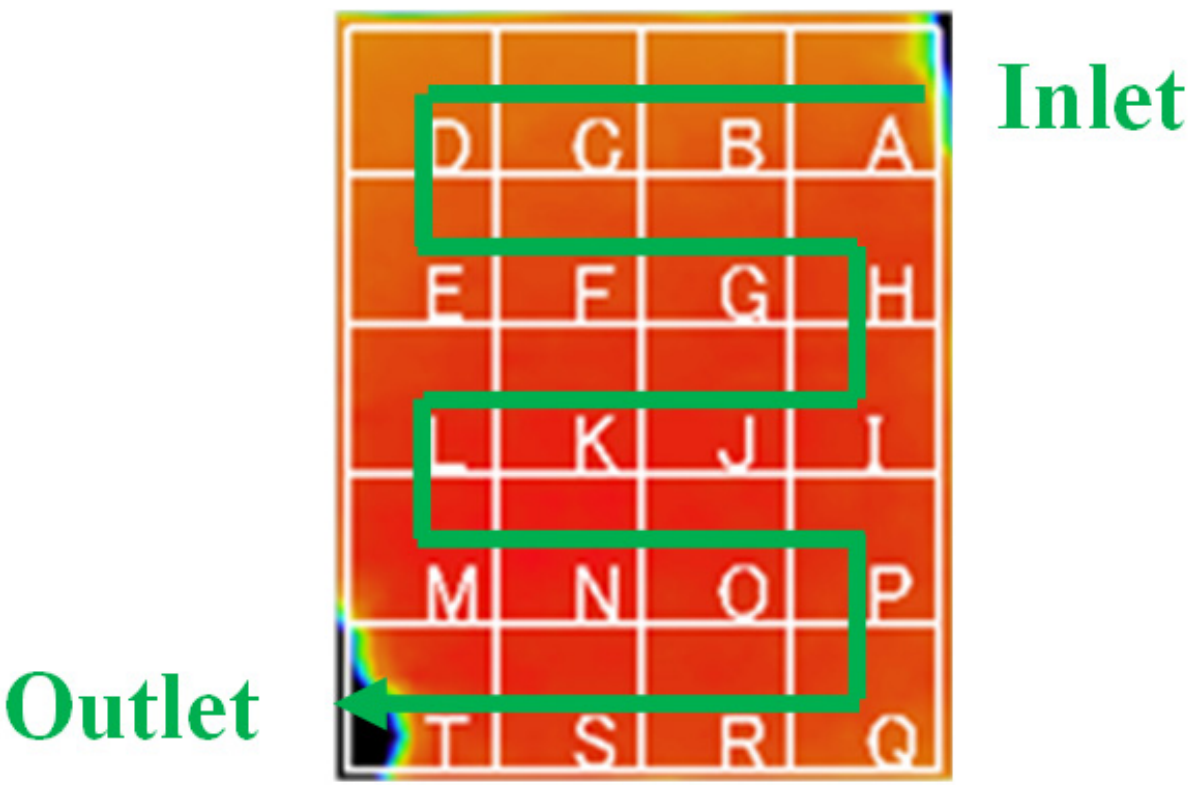

Figure 3. Segment of the temperature range. The 20 segment areas were named from A to T, along with the gas flow through the gas channel.

\section{Results and Discussion}

\subsection{Effects of Separator Thickness on Power Generation Characteristics with Changing Relative Humidity}

Figures 4-6 show comparisons of polarization curves among various RHs and $T_{\text {init }}$ for separator thicknesses of $2.0 \mathrm{~mm}$ (saddle thickness: $1.0 \mathrm{~mm}$, channel height: $1.0 \mathrm{~mm}$ ), $1.5 \mathrm{~mm}$ (saddle thickness: $0.5 \mathrm{~mm}$, channel height: $1.0 \mathrm{~mm}$ ) and $1.0 \mathrm{~mm}$ (saddle height: $0.5 \mathrm{~mm}$, channel height: $0.5 \mathrm{~mm}$ ), respectively. A80\%RH\&C80\%RH, A80\%RH\&C40\%RH, A $40 \%$ RH\&C $80 \%$ RH and A40\%RH\&C40\%RH were investigated. The $T_{\text {init }}$ values changed by $353 \mathrm{~K}, 363 \mathrm{~K}$ and $373 \mathrm{~K}$. Regarding polarization curves, the error level of the data was below 5\% under all experimental conditions. To highlight the effects of the separator thickness, Figures 7 and 8 show comparisons of polarization curves for different separators and $T_{\text {init }}$ values with $\mathrm{A} 80 \% \mathrm{RH} \& \mathrm{C} 80 \% \mathrm{RH}$ and $\mathrm{A} 40 \% \mathrm{RH} \& \mathrm{C} 40 \% \mathrm{RH}$, respectively. A $80 \%$ RH \&C $80 \%$ RH and A40\%RH\&C40\%RH were selected as well-humidified and dry conditions, respectively. In addition, Figure 9 shows a comparison of the relationship between the separator thickness and total voltage obtained at a current density of $0.80 \mathrm{~A} / \mathrm{cm}^{2}$ with an s.r. of 1.5. This condition was selected to indicate the in-plane temperature distribution data later from the various $T_{\text {init }}$ and relative humidity conditions.

It can be seen from Figures 4-6 that the effect of $\mathrm{RH}$ on the power generation characteristics is more significant when the separator thickness decreases. Especially, the power generation performance with $\mathrm{A} 40 \% \mathrm{RH} \& \mathrm{C} 40 \% \mathrm{RH}$ drops rapidly with the decrease in separator thickness. Since the heat capacity of the separator decreases with the decrease in separator thickness, the temperature of the cell using the thinner separator becomes higher after attaining the steady state via heat balance, with the surrounding temperature of $293 \mathrm{~K}$ being controlled by the air conditioner. A40\%RH\&C40\%RH is the dry condition, resulting from PEM and catalyst layer being dehydrated easily. The proton conductivity of PEM decreases due to the dehumidification of PEM at higher temperatures, resulting in a large ohmic overpotential [29]. With the low RH, it is harder to hydrate the ionomer in the 
cathode catalyst layer using the water that migrates through the PEM from the anode to the cathode, which is important for the performance of the $\mathrm{O}_{2}$ reduction reaction at the cathode [30]. The large ohmic overpotential is mainly caused by ionic and electronic resistances. The ionic resistance is associated with the resistance of the PEM and ionomer of the catalyst layer [31]. Due to the increase in ohmic overpotential, the power generation performance with A40\%RH\&C40\%RH declines significantly compared to the other RHs.

(a)

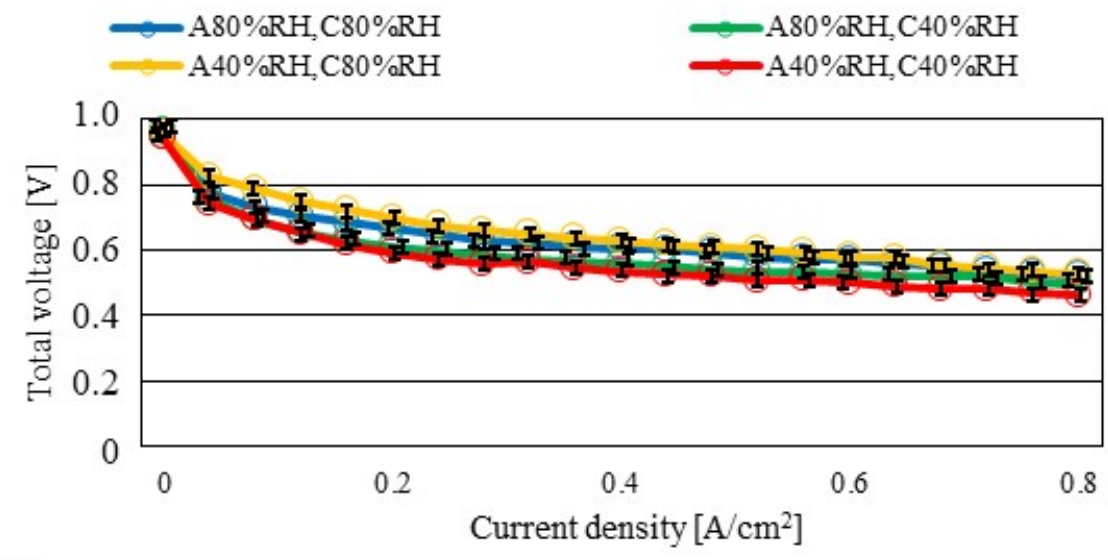

(b)

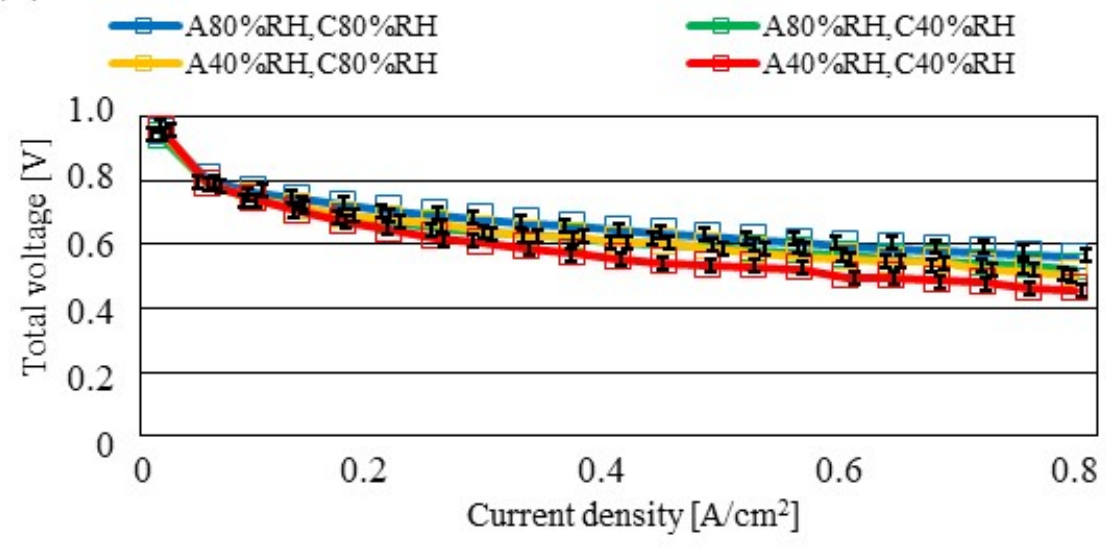

(c)

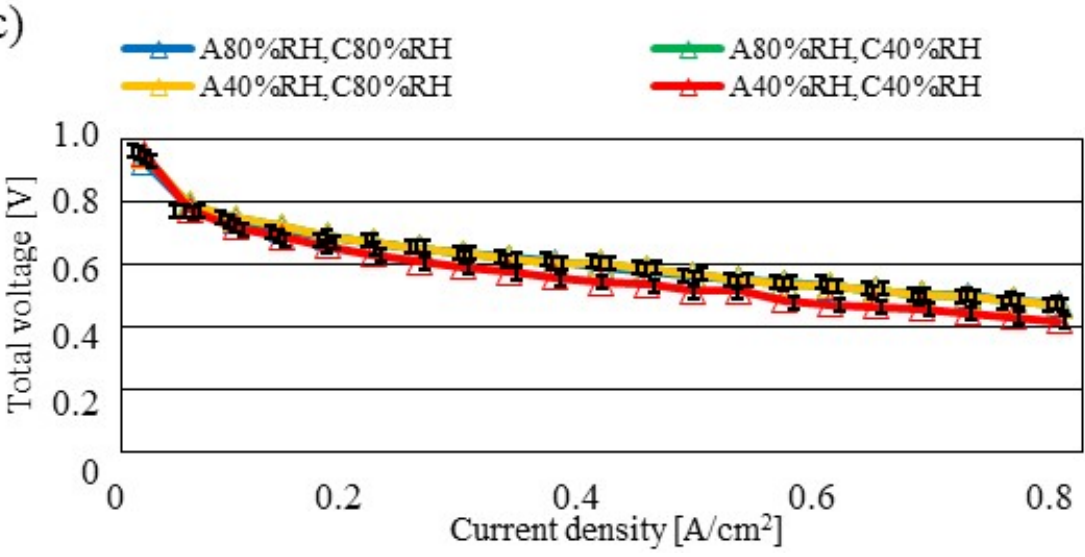

Figure 4. Comparison of polarization curves among different RHs for a separator thickness of $2.0 \mathrm{~mm}$ : (a) $T_{\text {init }}=353 \mathrm{~K}$; (b) $T_{\text {init }}=363 \mathrm{~K}$; (c) $T_{\text {init }}=373 \mathrm{~K} \mathrm{~A} 80 \% \mathrm{RH} \& \mathrm{C} 80 \% \mathrm{RH}, \mathrm{A} 80 \% \mathrm{RH} \& \mathrm{C} 40 \% \mathrm{RH}$, A40\%RH\&C $80 \%$ RH and A40\%RH\&C40\%RH were investigated. 
(a)
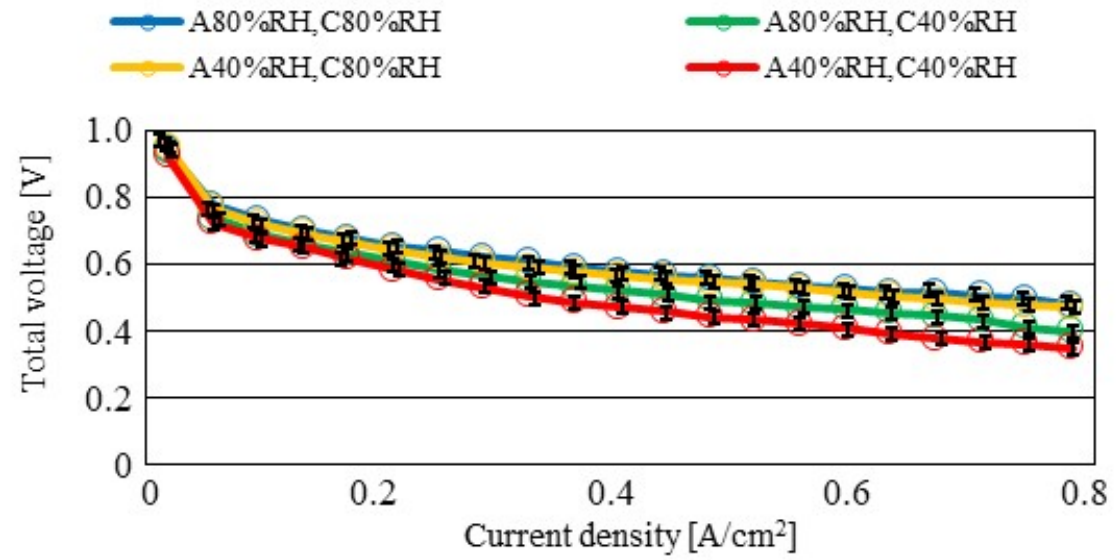

(b)

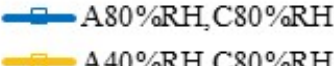

$=\mathrm{A} 80 \% \mathrm{RH}, \mathrm{C} 40 \% \mathrm{RH}$

$=\mathrm{A} 40 \% \mathrm{RH} \mathrm{C} 80 \% \mathrm{RH}$

$\mathrm{A} 40 \% \mathrm{RH} \mathrm{C} 40 \% \mathrm{RH}$

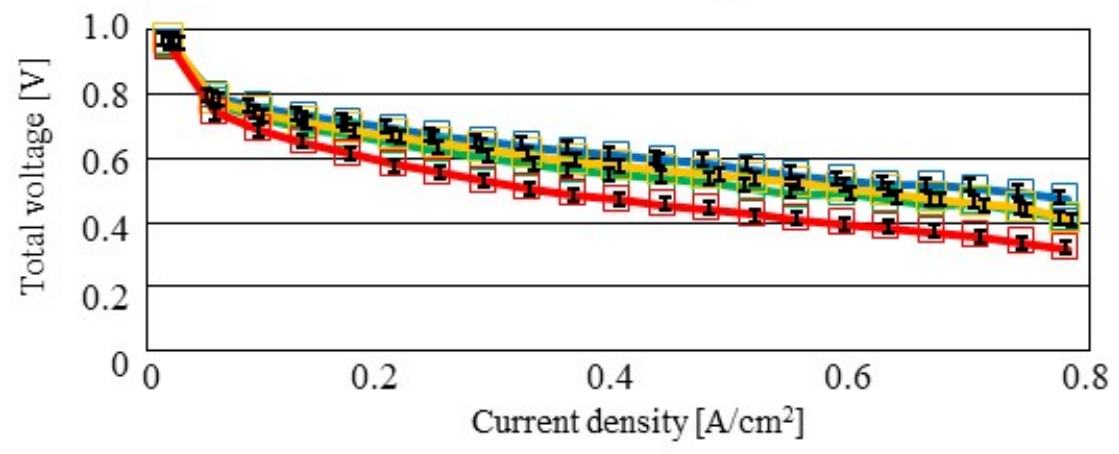

(c) $-\mathrm{A} 80 \% \mathrm{RH}, \mathrm{C} 80 \% \mathrm{RH}$

$=\mathrm{A} 80 \% \mathrm{RH}, \mathrm{C} 40 \% \mathrm{RH}$

$=\mathrm{A} 40 \% \mathrm{RH}, \mathrm{C} 80 \% \mathrm{RH}$

$\longrightarrow \mathrm{A} 40 \% \mathrm{RH}, \mathrm{C} 40 \% \mathrm{RH}$

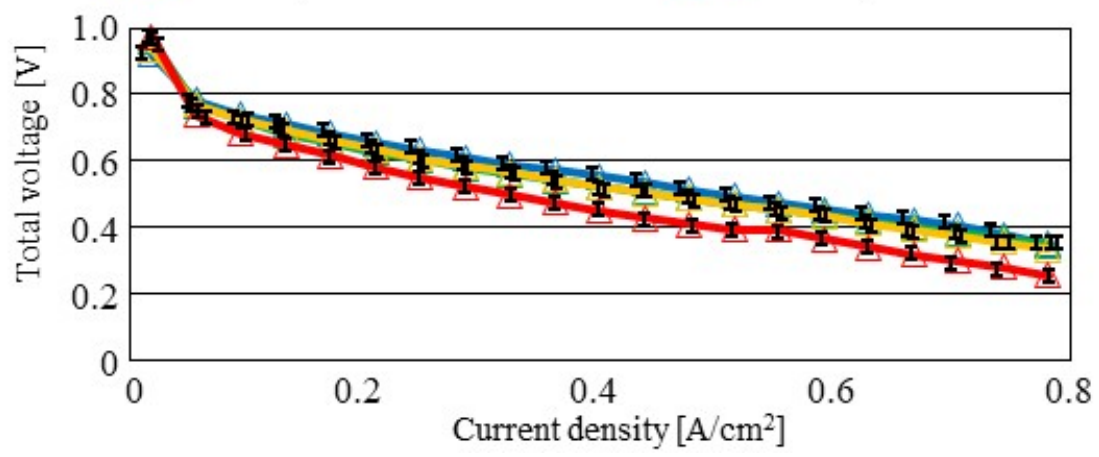

Figure 5. Comparison of polarization curves among different $\mathrm{RHs}$ for a separator thickness of $1.5 \mathrm{~mm}$ : (a) $T_{\text {init }}=353 \mathrm{~K}$; (b) $T_{\text {init }}=363 \mathrm{~K}$; (c) $T_{\text {init }}=373 \mathrm{~K} . \mathrm{A} 80 \% \mathrm{RH} \& \mathrm{C} 80 \% \mathrm{RH}, \mathrm{A} 80 \% \mathrm{RH} \& \mathrm{C} 40 \% \mathrm{RH}$, $\mathrm{A} 40 \% \mathrm{RH} \& \mathrm{C} 80 \% \mathrm{RH}$ and $\mathrm{A} 40 \% \mathrm{RH} \& \mathrm{C} 40 \% \mathrm{RH}$ were investigated. 
(a)

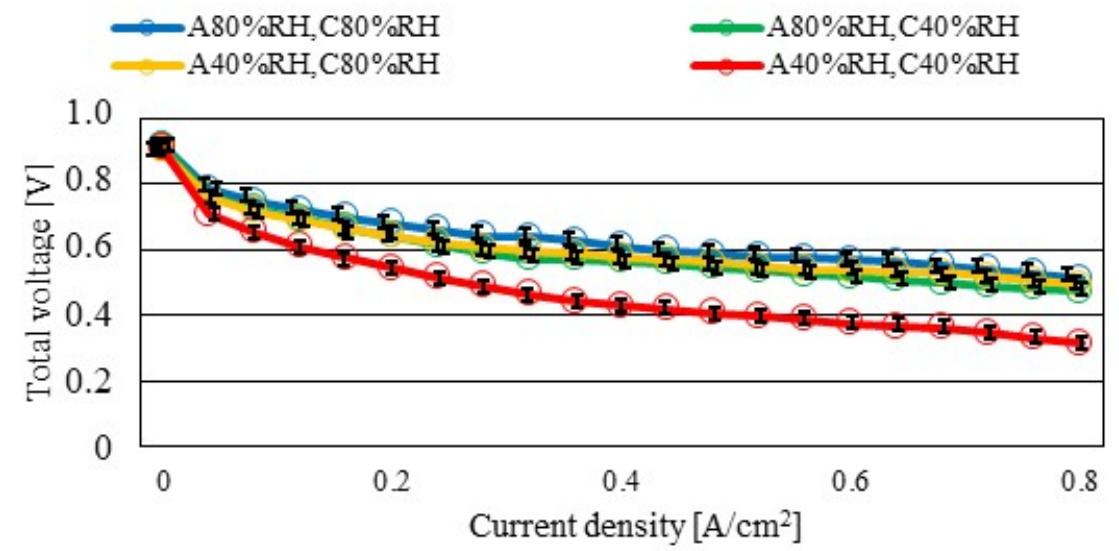

(b)

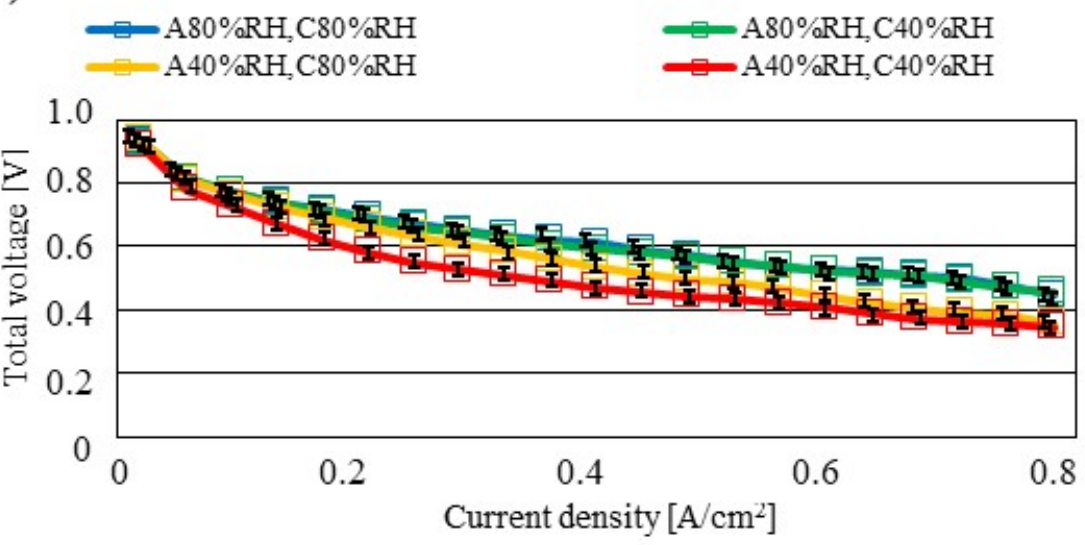

(c)

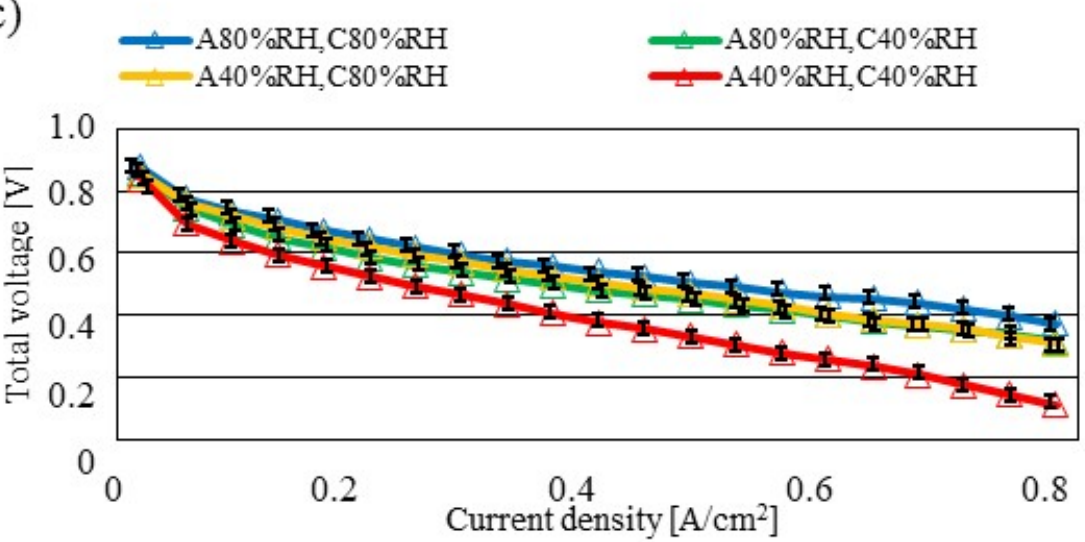

Figure 6. Comparison of polarization curves among different RHs for a separator thickness of $1.0 \mathrm{~mm}$ : (a) $T_{\text {init }}=353 \mathrm{~K}$; (b) $T_{\text {init }}=363 \mathrm{~K}$; (c) $T_{\text {init }}=373 \mathrm{~K} . \mathrm{A} 80 \% \mathrm{RH} \& \mathrm{C} 80 \% \mathrm{RH}, \mathrm{A} 80 \% \mathrm{RH} \& \mathrm{C} 40 \% \mathrm{RH}$, A40\%RH\&C $80 \%$ RH and A40\%RH\&C40\%RH were investigated. 
(a)

$\multimap \mathrm{Sa}: 1.0 \mathrm{~mm}, \mathrm{Ch}: 1.0 \mathrm{~mm} \quad \square \mathrm{Sa}: 0.5 \mathrm{~mm}, \mathrm{Ch}: 1.0 \mathrm{~mm}$ $\triangle \mathrm{Sa}: 0.5 \mathrm{~mm}, \mathrm{Ch}: 0.5 \mathrm{~mm}$

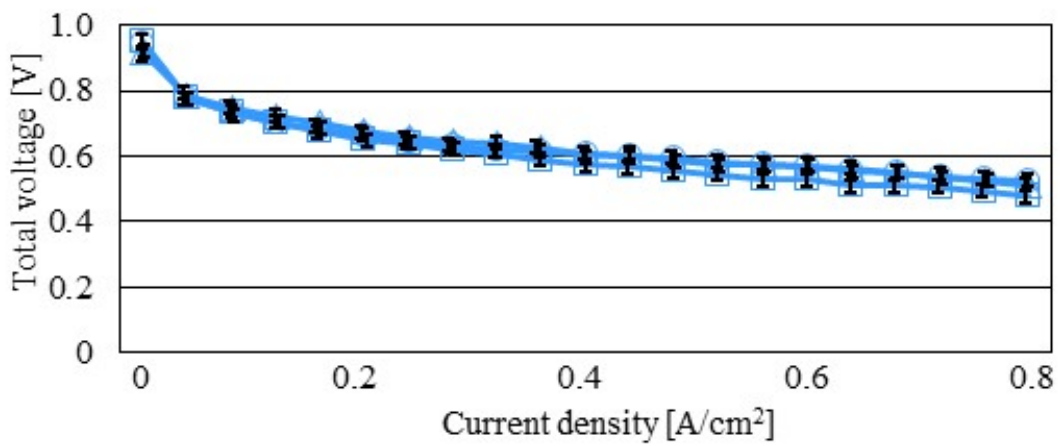

(b)

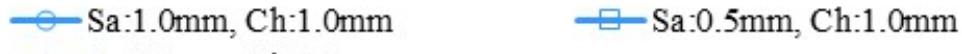
$\simeq \mathrm{Sa}: 0.5 \mathrm{~mm}, \mathrm{Ch}: 0.5 \mathrm{~mm}$

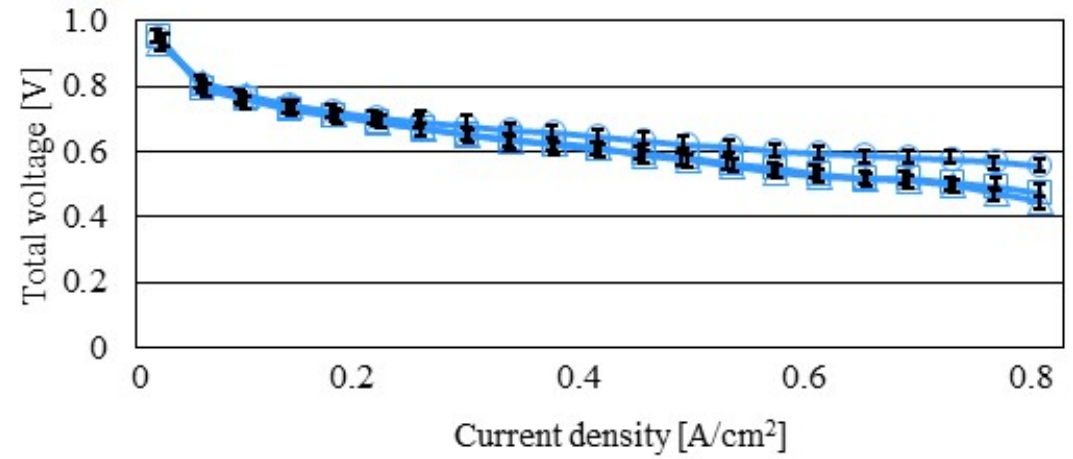

(c)

$\frown \mathrm{Sa}: 1.0 \mathrm{~mm}, \mathrm{Ch}: 1.0 \mathrm{~mm}$

$\square \mathrm{Sa}: 0.5 \mathrm{~mm}, \mathrm{Ch}: 1.0 \mathrm{~mm}$
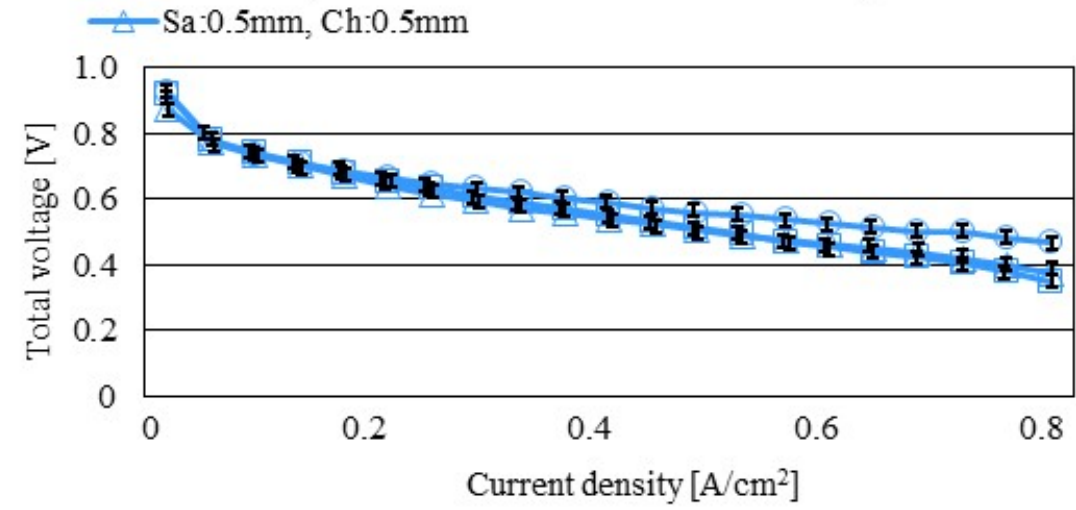

Figure 7. Comparison of polarization curves among different separator thicknesses with A80\%RH\&C80\%RH: (a) $T_{\text {init }}=353 \mathrm{~K}$; (b) $T_{\text {init }}=363 \mathrm{~K}$; (c) $T_{\text {init }}=373 \mathrm{~K}$. 
(a)

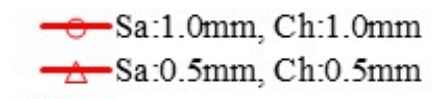

$\longrightarrow \mathrm{Sa}: 0.5 \mathrm{~mm}, \mathrm{Ch}: 1.0 \mathrm{~mm}$

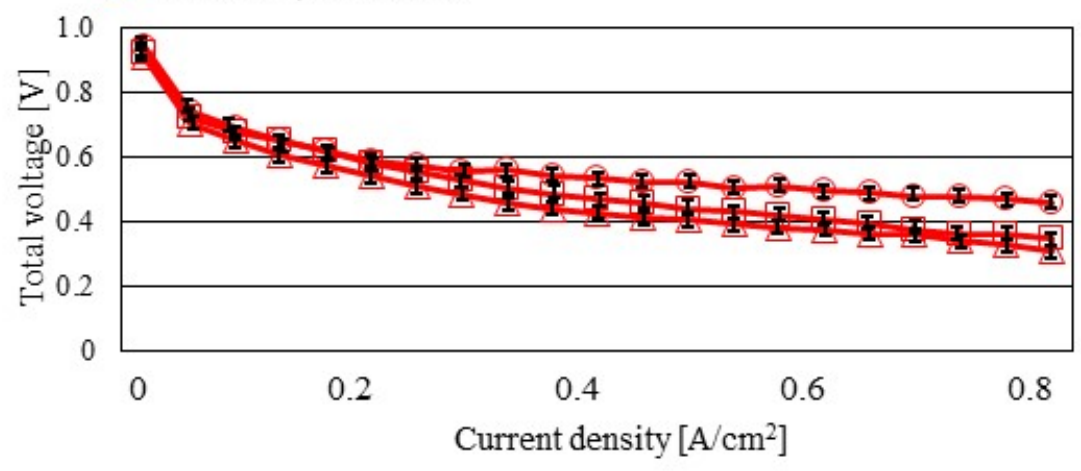

(b)
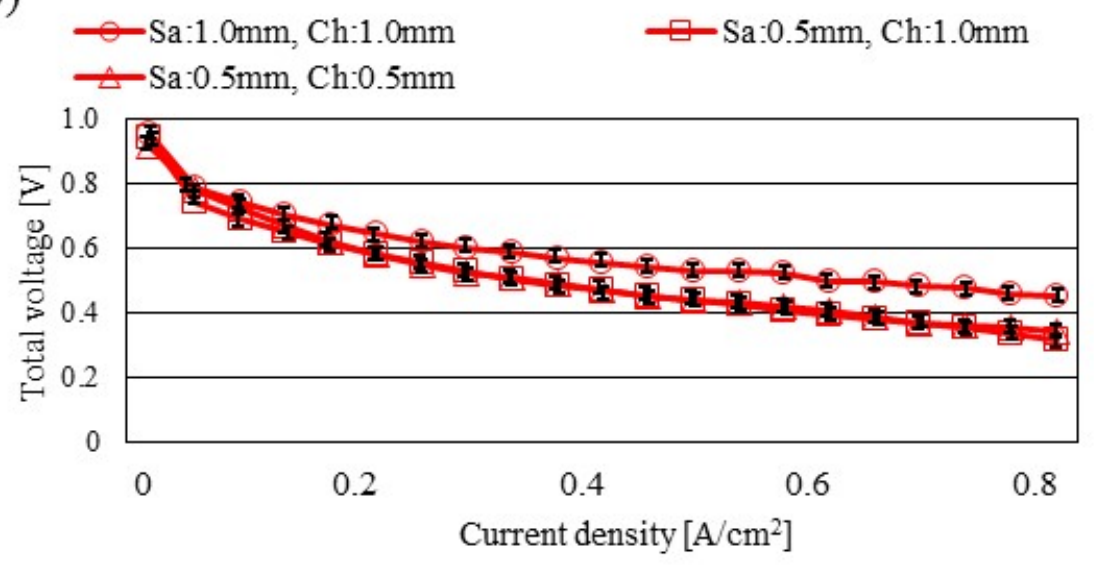

(c)
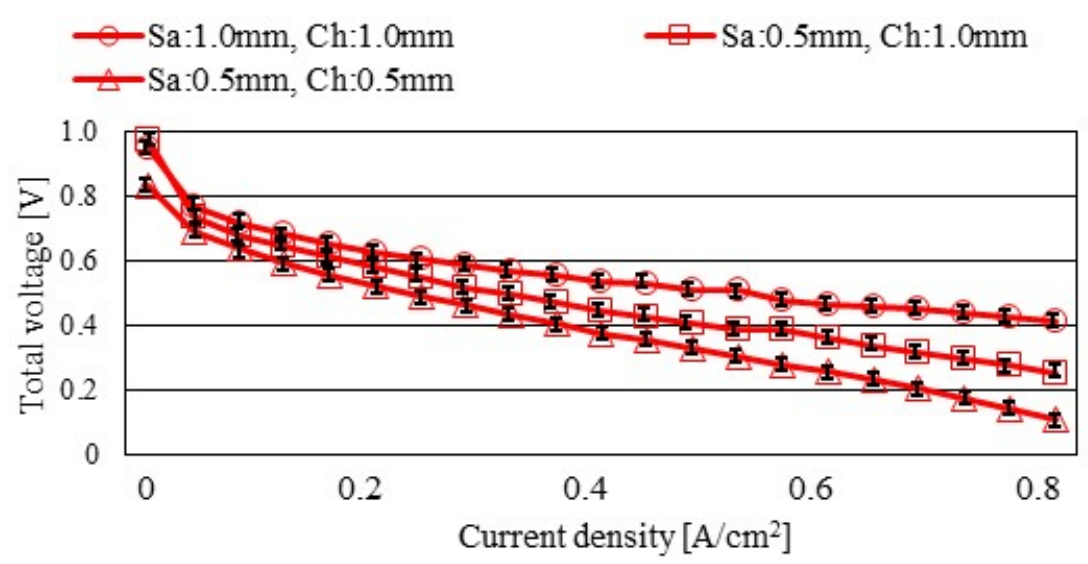

Figure 8. Comparison of polarization curves among different separator thicknesses with A40\%RH\&C40\%RH: (a) $T_{\text {init }}=353 \mathrm{~K}$; (b) $T_{\text {init }}=363 \mathrm{~K}$; (c) $T_{\text {init }}=373 \mathrm{~K}$. 
(a)

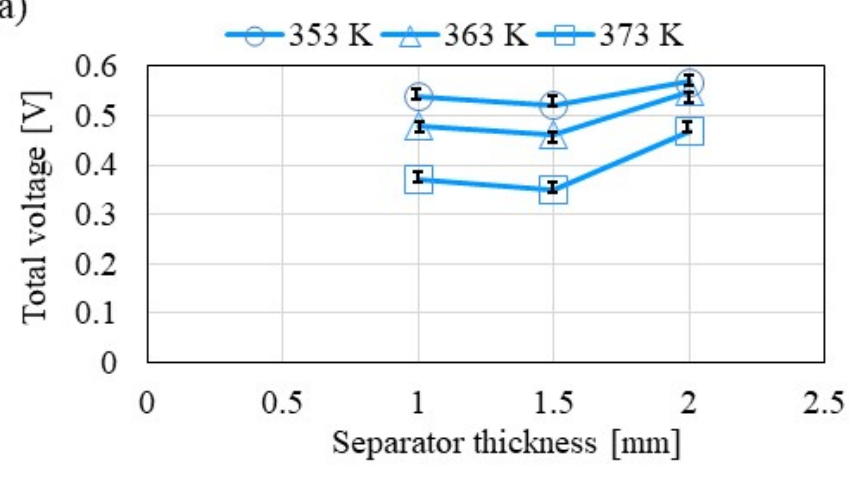

(b)

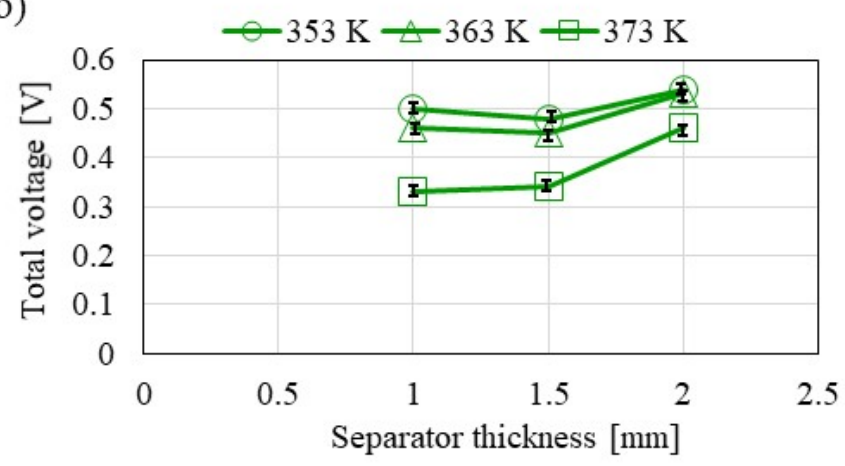

(c)

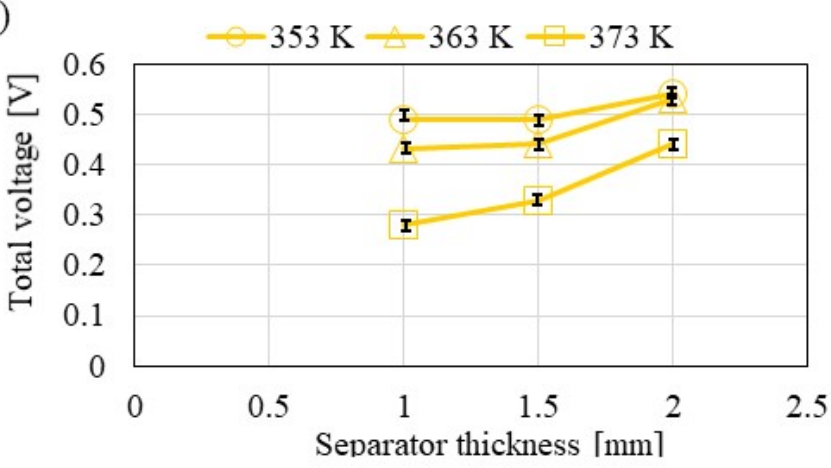

(d)

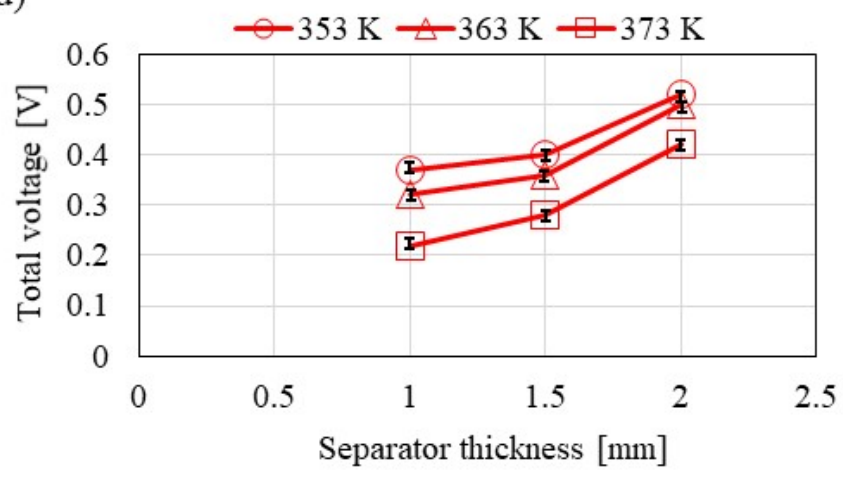

Figure 9. Comparison of the relationship between the separator thickness and total voltage obtained at a current density of $0.80 \mathrm{~A} / \mathrm{cm}^{2}$ with an s.r. of 1.5 . This condition was selected to show the in-plane temperature distribution data later, among different $T_{\text {init }}$ and $\mathrm{RH}$ conditions: (a) $\mathrm{A} 80 \% \mathrm{RH}, \mathrm{C} 80 \% \mathrm{RH}$; (b) $\mathrm{A} 80 \% \mathrm{RH}, \mathrm{C} 40 \% \mathrm{RH}$; (c) $\mathrm{A} 40 \% \mathrm{RH}, \mathrm{C} 80 \% \mathrm{RH}$; (d) $\mathrm{A} 40 \% \mathrm{RH}, \mathrm{C} 40 \% \mathrm{RH}$. 
In addition, it can be found from Figures 4-6 that the power generation performance at the high current density declines with the increase in $T_{\text {init }}$. Especially, this trend is more significant for the thinner separator thickness. The ohmic overpotential causes a strong effect on the cell performance at high current densities, since the heat generated by the electrochemical reaction increases due to the high fuel and oxide consumption [20]. In addition, the concentration overpotential also influences the cell performance at high current densities because of the increase in $\mathrm{O}_{2}$ consumption [20]. We have to consider the kinetics of the catalyst as well as the proton conductivity of PEM in the discussion of these phenomena. The kinetics of the catalyst becomes faster with the increase in temperature, while $\mathrm{RH}$ influences the performance of the $\mathrm{O}_{2}$ reduction reaction that occurs on the ionomer in the cathode catalyst layer [30]. There is an optimum $\mathrm{H}_{2} \mathrm{O}$ saturation for the ionomer in the cathode catalyst layer. In addition, the proton conductivity of PEM is influenced by temperature and RH. According to the literature [29,32], the proton conductivity of PEM increases with the increase in temperature as well as the increase in $\mathrm{RH}$. Since the saturation pressure of the $\mathrm{H}_{2} \mathrm{O}$ vapor increases with the increase in temperature exponentially [20], it is easy to dehydrate PEM at $T_{\text {init }}=373 \mathrm{~K}$ compared to $T_{\text {init }}=353 \mathrm{~K}$, meaning that the proton conductivity of PEM decreases at $T_{\text {init }}=373 \mathrm{~K}$. If the proton conductivity of PEM decreases, the performance of the $\mathrm{O}_{2}$ reduction reaction decreases due to the lack of protons. In addition, since the hydration of PEM is not sufficient at $T_{\text {init }}=373 \mathrm{~K}$, a high partial $\mathrm{O}_{2}$ pressure is needed to progress the $\mathrm{O}_{2}$ reduction reaction [20]. As a result, it is thought that the $\mathrm{O}_{2}$ consumption decreases at $T_{\text {init }}=373 \mathrm{~K}$. The concentration overpotential increases with the decrease in $\mathrm{O}_{2}$ consumption, resulting in the current density decreasing at $T_{\text {init }}=373 \mathrm{~K}$. In addition, the ohmic overpotential, which is influenced by the proton conductivity of the PEM, increases with the decrease in separator thickness due to the temperature increased, as described above [33]. Consequently, it is revealed that the power generation performance at the high current density declines with the increase in $T_{\text {init }}$ for the thinner separator thickness.

According to Figures 7 and 8, the voltage drop at the high current density increases with the decrease in separator thickness. This tendency is remarkable under low-RH conditions, as shown in Figure 8. Therefore, it is thought that the drying impact influences this.

According to Figure 9, we can see that the total voltage increases with the increase in separator thickness. In addition, the total voltage decreases with the increase in $T_{\text {init }}$. Moreover, it is clarified that the impact of the separator thickness on the total voltage is significant with $\mathrm{A} 40 \% \mathrm{RH} \& \mathrm{C} 40 \% \mathrm{RH}$. This figure summarizes the above results and comments.

\subsection{Effect of Separator Thickness on In-Plane Temperature Distribution with Changing Relative Humidity}

Figures 10-12 show comparisons of in-plane temperature distributions at the anode side among different RHs and $T_{\text {init }}$ values for separator thicknesses of $2.0 \mathrm{~mm}, 1.5 \mathrm{~mm}$ and $1.0 \mathrm{~mm}$, respectively. A80\%RH\&C80\%RH, A80\%RH\&C40\%RH, A40\%RH\&C80\%RH and $\mathrm{A} 40 \% \mathrm{RH} \& \mathrm{C} 40 \% \mathrm{RH}$ were investigated. The $T_{\text {init }}$ values changed by $353 \mathrm{~K}, 363 \mathrm{~K}$ and $373 \mathrm{~K}$. The effect of the stoichiometric ratio of the supply gas on the in-plane temperature distribution has not been confirmed; therefore, this paper shows the results obtained for a stoichiometric ratio of 1.5. Regarding the in-plane temperature distribution, the error level of data was below 3\% under all experimental conditions. To investigate the effect of the separator thickness, Figures 13 and 14 show the in-plane temperature distribution among different separator thicknesses and $T_{\text {init }}$ values with A80\%RH\&C80\%RH and $\mathrm{A} 40 \% \mathrm{RH} \& \mathrm{C} 40 \% \mathrm{RH}$, respectively. A80\%RH\&C $80 \% \mathrm{RH}$ and $\mathrm{A} 40 \% \mathrm{RH} \& \mathrm{C} 40 \% \mathrm{RH}$ were selected as well-humidified and dry conditions, respectively. In addition, the relationship between the maximum temperature difference $\left(T_{\max }-T_{\min }\right)$ and $T_{\text {init }}$ is shown in Figure 15. 
According to Figures 10-12, the temperature drops at positions D, L and T for the separator thickness of $2.0 \mathrm{~mm}$. On the other hand, the temperature increases from the inlet to the outlet by approximately $2 \mathrm{~K}$ gradually for separator thicknesses of $1.5 \mathrm{~mm}$ and $1.0 \mathrm{~mm}$. The reason is thought to be that it is easy to dry out the PEM and catalyst layer at separator thicknesses of $1.5 \mathrm{~mm}$ and $1.0 \mathrm{~mm}$, which have a small heat capacity and thermal resistance [26] compared to that of $2.0 \mathrm{~mm}$. In other words, $\mathrm{H}_{2} \mathrm{O}$ vapor is easy to be condensed into a liquid state, since the separator thickness of $2.0 \mathrm{~mm}$ has high heat capacity and thermal resistance. The reason why the difference in heat capacity influences the cell temperature is discussed below.

(a)

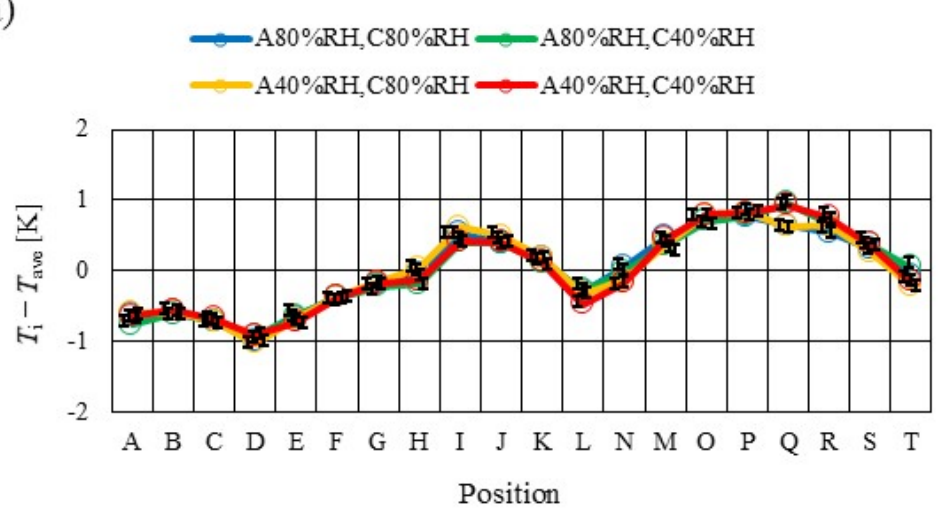

(b)

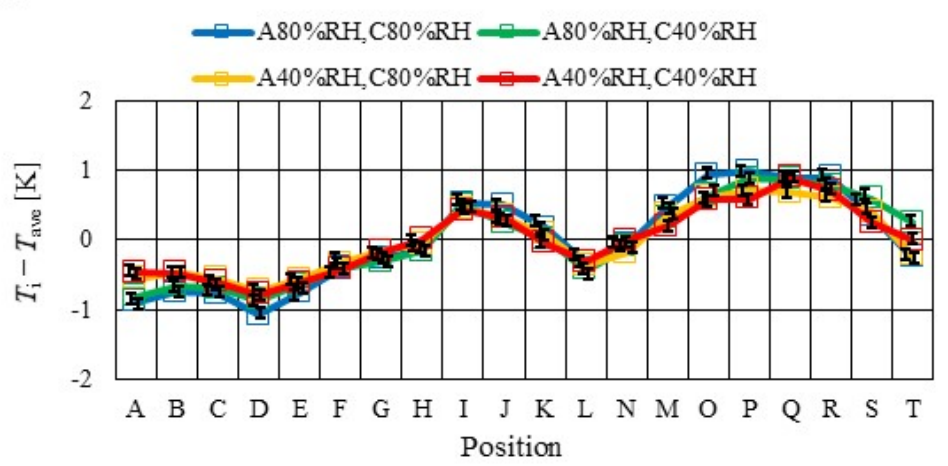

(c)

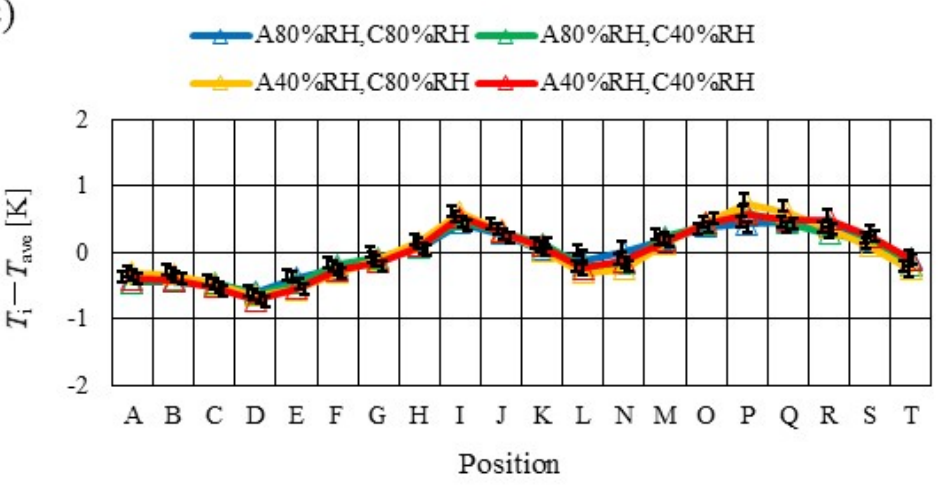

Figure 10. Comparison of the in-plane temperature distribution at the anode side among different RHs in the case of the separator thickness of $2.0 \mathrm{~mm}$ : (a) $T_{\text {init }}=353 \mathrm{~K}$; (b) $T_{\text {init }}=363 \mathrm{~K}$; (c) $T_{\text {init }}=373 \mathrm{~K}$. 
(a)

$-\mathrm{A} 80 \% \mathrm{RH}, \mathrm{C} 80 \% \mathrm{RH} \longrightarrow \mathrm{A} 80 \% \mathrm{RH}, \mathrm{C} 40 \% \mathrm{RH}$

$-\mathrm{A} 40 \% \mathrm{RH}, \mathrm{C} 80 \% \mathrm{RH}-\mathrm{A} 40 \% \mathrm{RH}, \mathrm{C} 40 \% \mathrm{RH}$

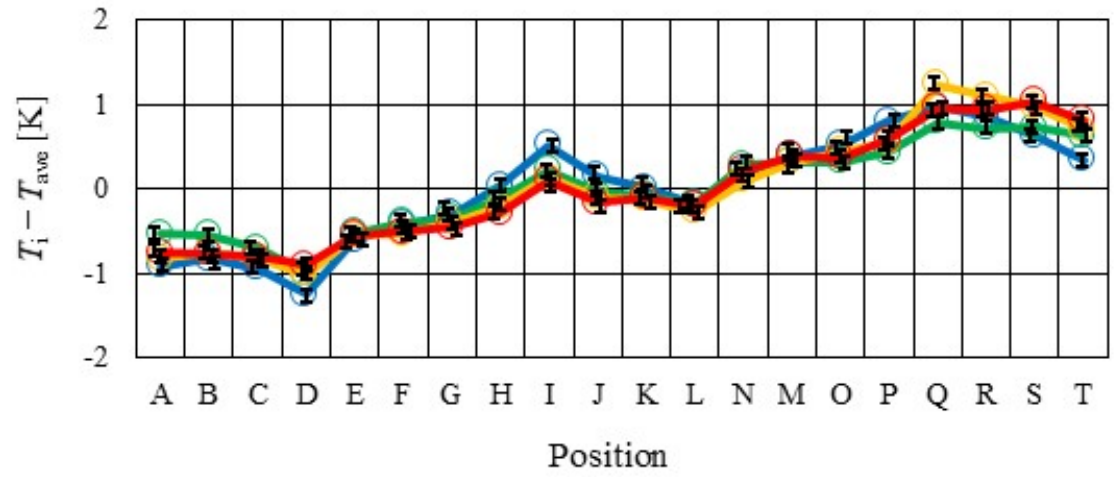

(b)
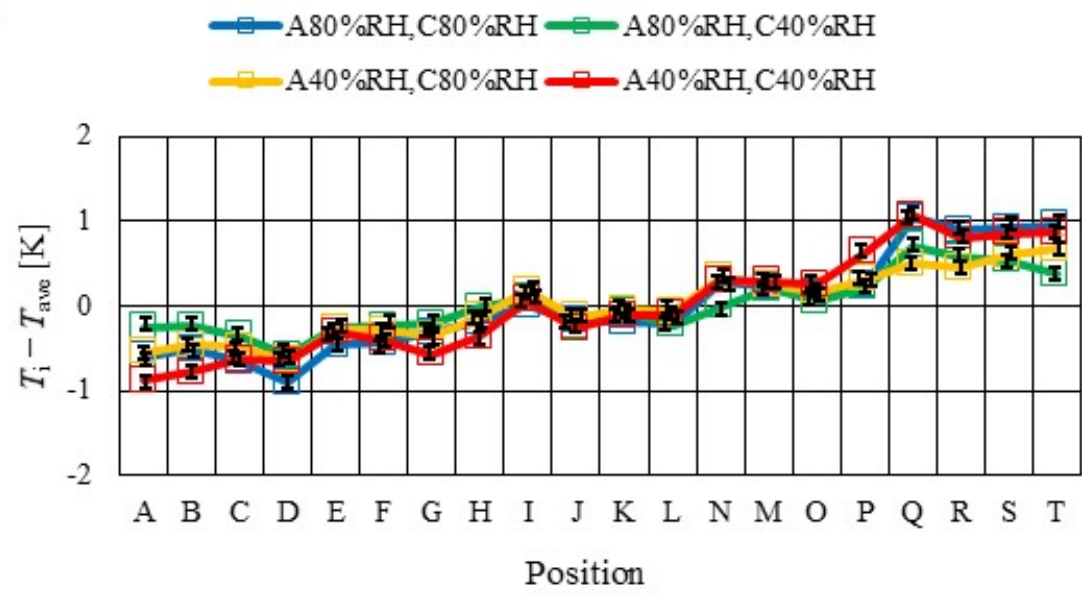

(c)

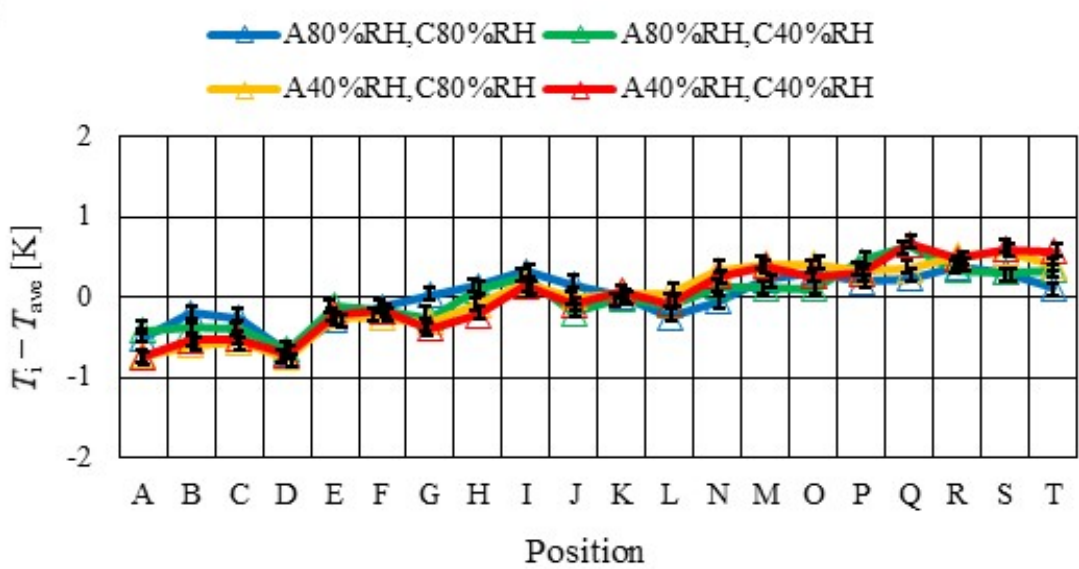

Figure 11. Comparison of the in-plane temperature distribution at the anode side among different RHs in the case of the separator thickness of $1.5 \mathrm{~mm}$ : (a) $T_{\text {init }}=353 \mathrm{~K} ;$ (b) $T_{\text {init }}=363 \mathrm{~K}$; (c) $T_{\text {init }}=373 \mathrm{~K}$. 
(a)
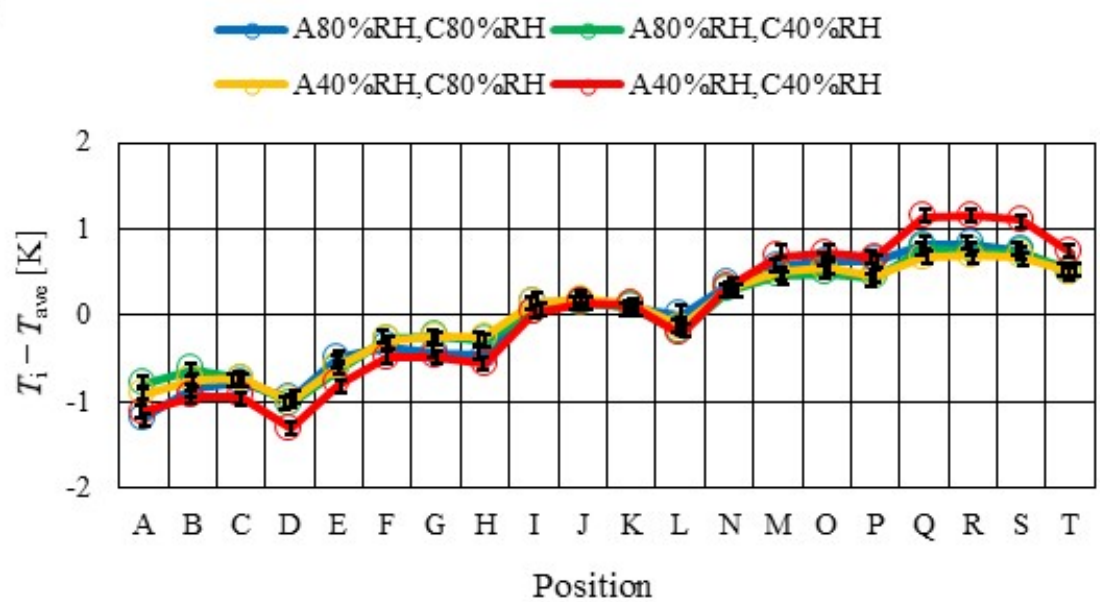

(b)

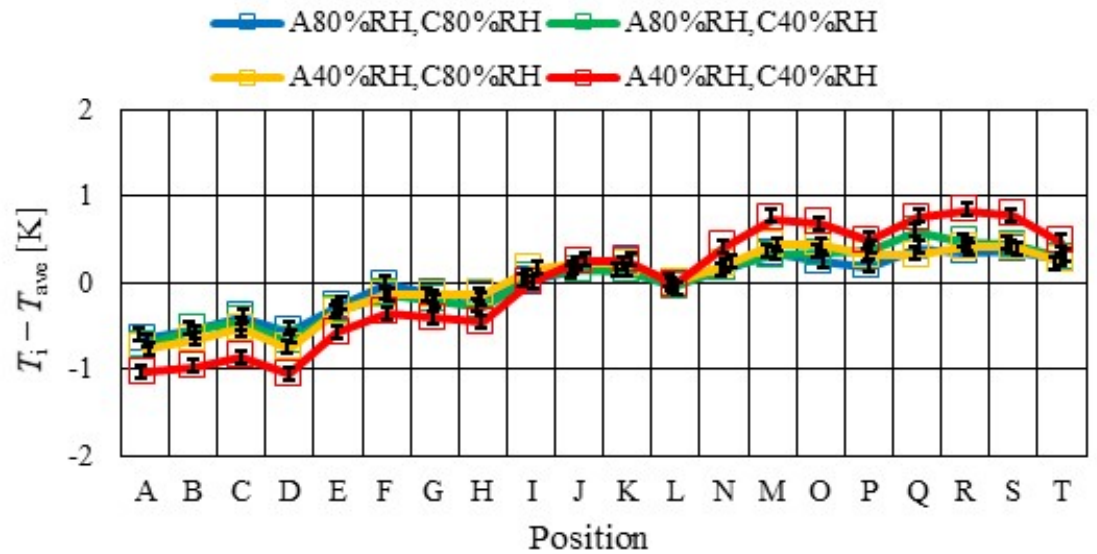

(c)

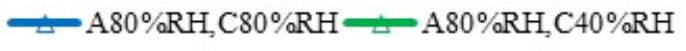

$-\mathrm{A} 40 \% \mathrm{RH}, \mathrm{C} 80 \% \mathrm{RH}=\mathrm{A} 40 \% \mathrm{RH}, \mathrm{C} 40 \% \mathrm{RH}$

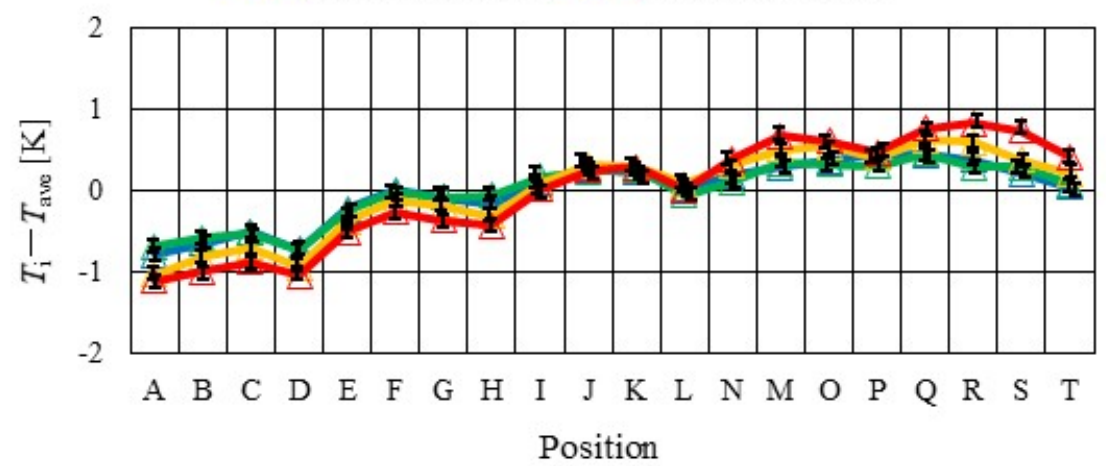

Figure 12. Comparison of the in-plane temperature distribution at the anode side among different RHs in the case of the separator thickness of $1.5 \mathrm{~mm}$ : (a) $T_{\text {init }}=353 \mathrm{~K}$; (b) $T_{\text {init }}=363 \mathrm{~K}$; (c) $T_{\text {init }}=373 \mathrm{~K}$. 
(a)

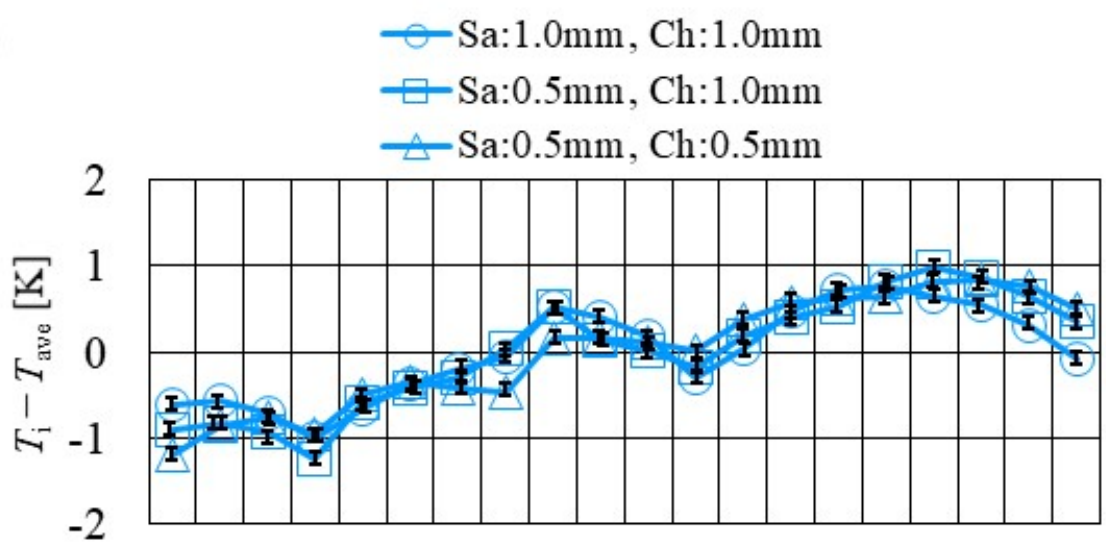

A B C D E F G H I J K L N M P Q R S T Position

(b)

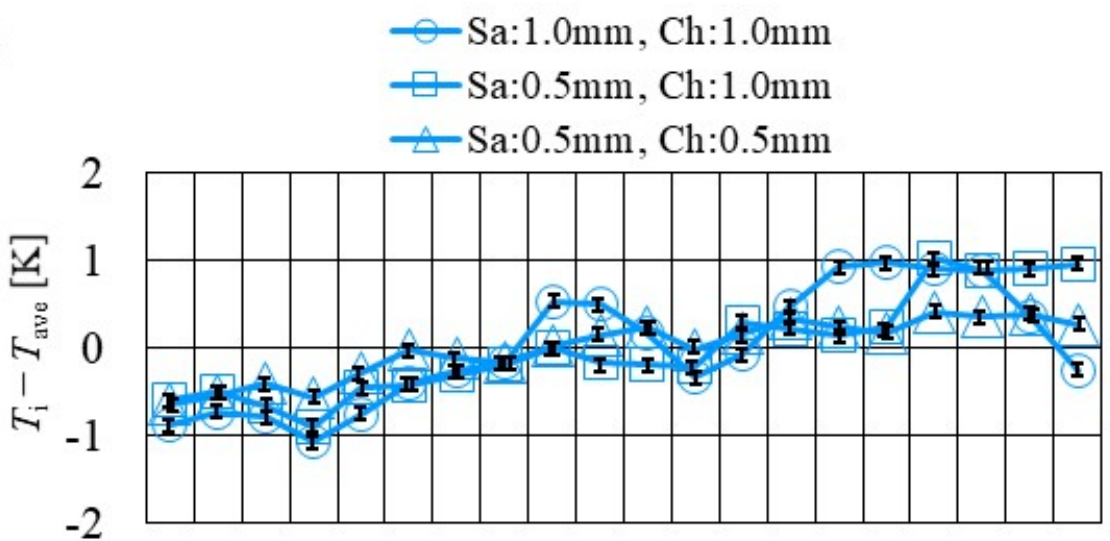

A B C D E F G H I K L NMOP Q R S T Position

(c) $\frown \mathrm{Sa}: 1.0 \mathrm{~mm}, \mathrm{Ch}: 1.0 \mathrm{~mm}$ $\square \mathrm{Sa}: 0.5 \mathrm{~mm}, \mathrm{Ch}: 1.0 \mathrm{~mm}$ $\triangle \mathrm{Sa}: 0.5 \mathrm{~mm}, \mathrm{Ch}: 0.5 \mathrm{~mm}$

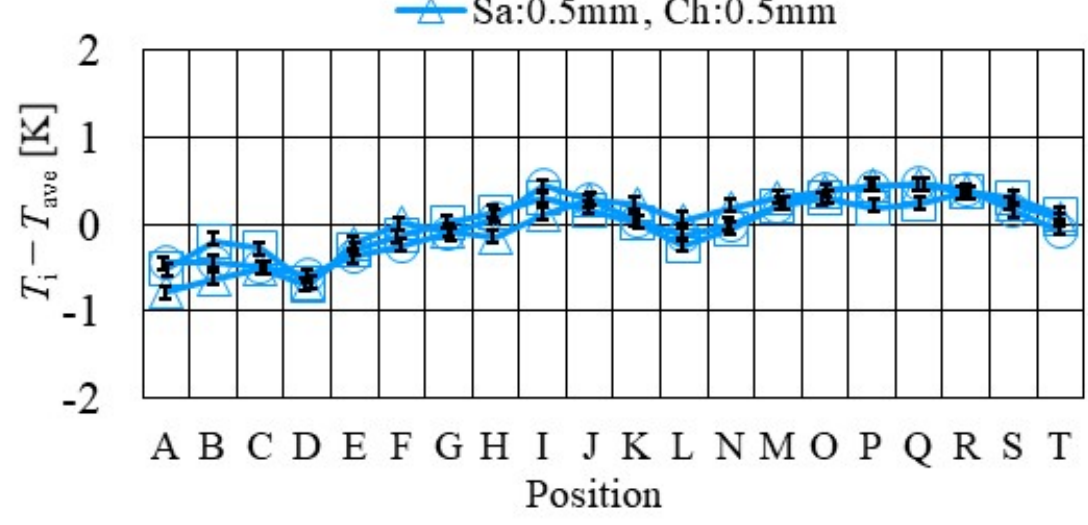

Figure 13. Comparison of the in-plane temperature distribution at the anode side among different separator thicknesses with A80\%RH\&C80\%RH: (a) $T_{\text {init }}=353 \mathrm{~K}$; (b) $T_{\text {init }}=363 \mathrm{~K}$; (c) $T_{\text {init }}=373 \mathrm{~K}$. 
(a)

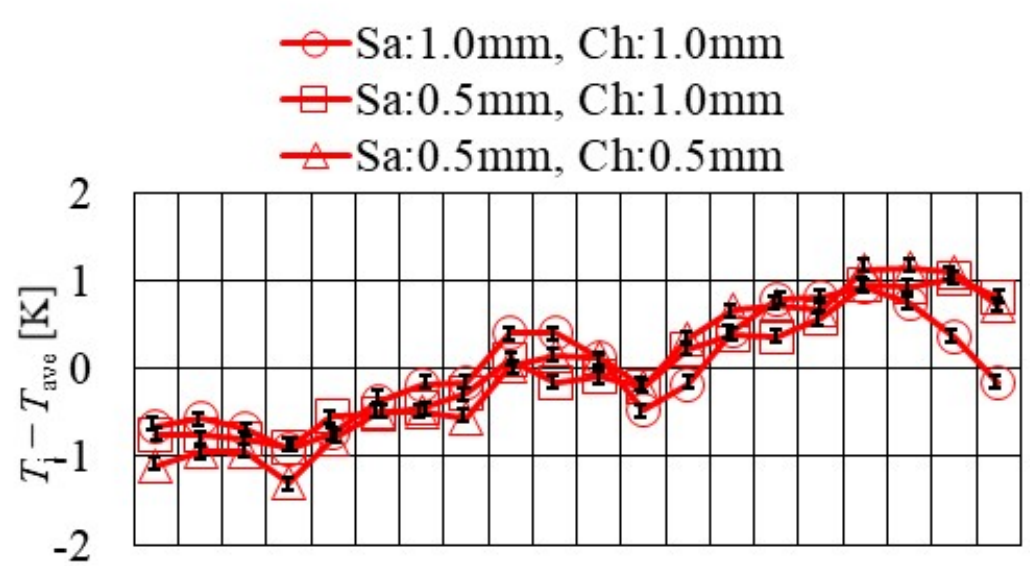

A B C D E F G H I I J J K L NMO P QR S T

(b)

-Sa: $1.0 \mathrm{~mm}, \mathrm{Ch}: 1.0 \mathrm{~mm}$

—-Sa: $0.5 \mathrm{~mm}, \mathrm{Ch}: 1.0 \mathrm{~mm}$

$\triangle \mathrm{Sa}: 0.5 \mathrm{~mm}$, Ch: $0.5 \mathrm{~mm}$

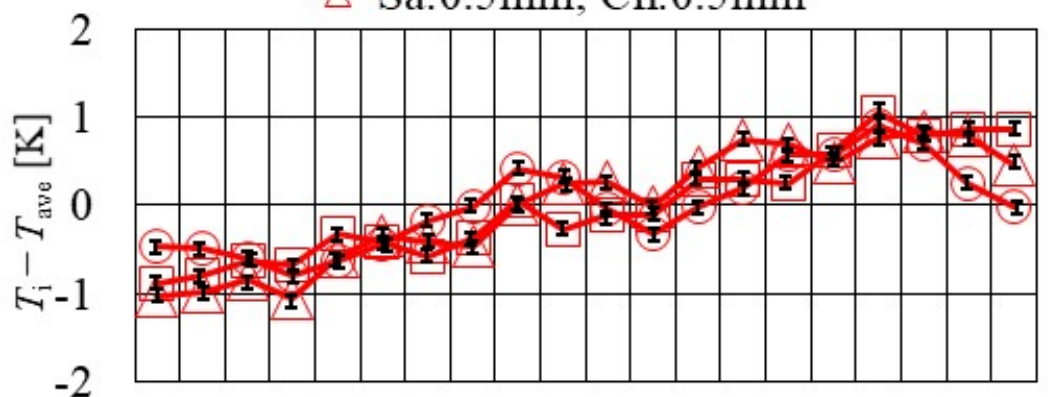

A B C D E F G H I J K L NMOP Q R S T

(c)
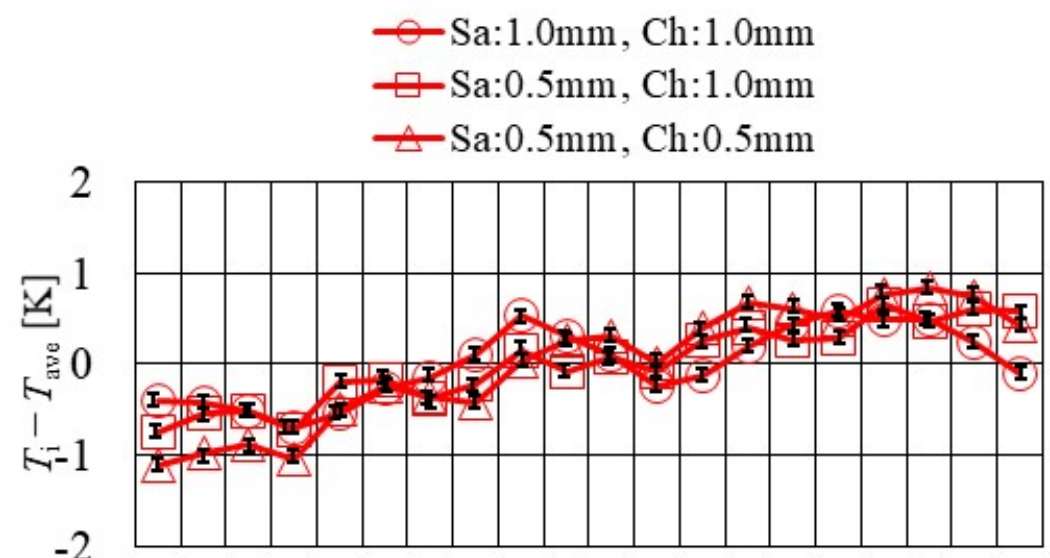

A B C D E F G H I J K L NMO P Q R S T Position

Figure 14. Comparison of the in-plane temperature distribution at the anode side among different separator thicknesses with A40\%RH\&C40\%RH: (a) $T_{\text {init }}=353 \mathrm{~K}$; (b) $T_{\text {init }}=363 \mathrm{~K}$; (c) $T_{\text {init }}=373 \mathrm{~K}$. 
(a)

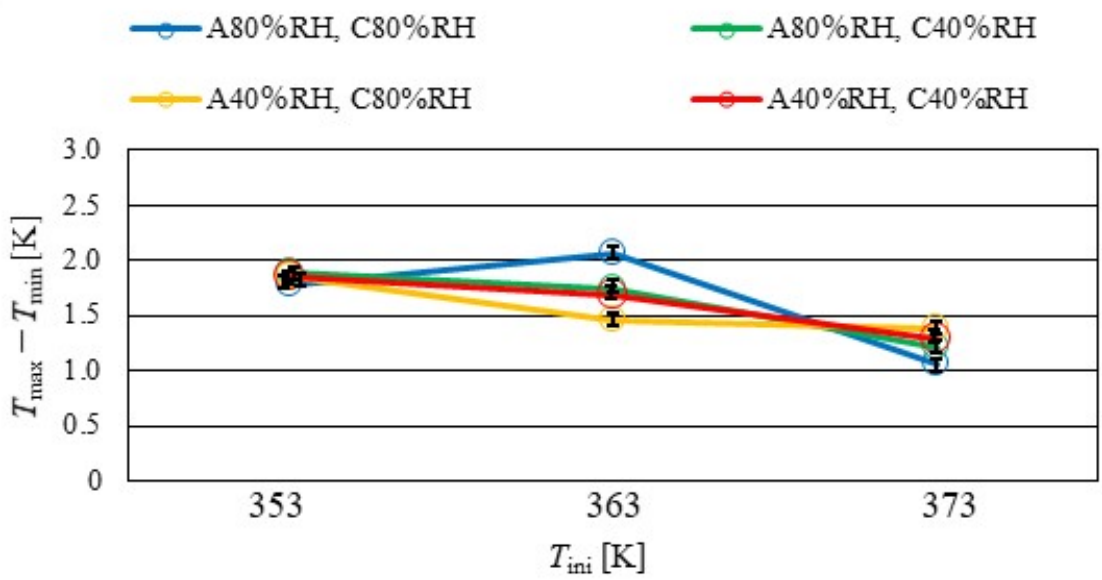

(b)

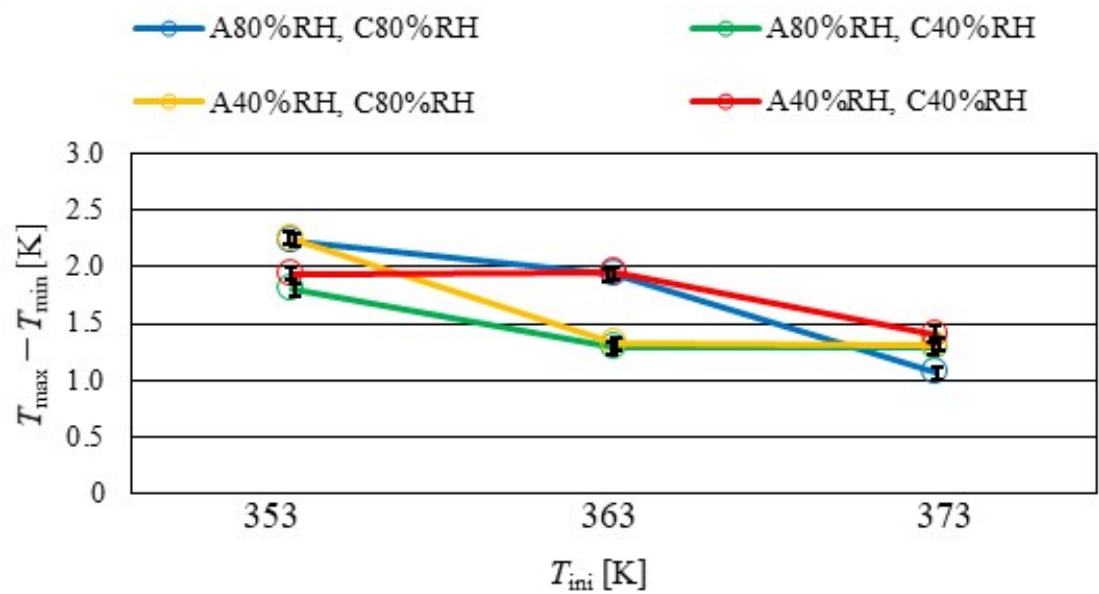

(c)

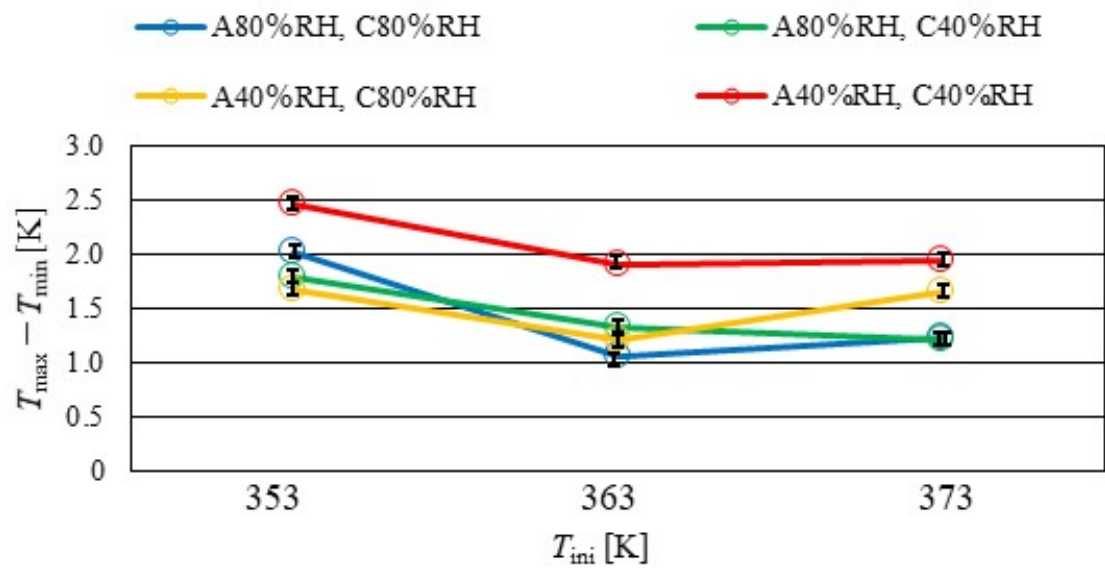

Figure 15. Comparison of relationship between $T_{\text {init }}$ and temperature difference $T_{\max }-T_{\min }$ at the anode side among different RHs: (a) $2.0 \mathrm{~mm}$; (b) $1.5 \mathrm{~mm}$; (c) $1.0 \mathrm{~mm}$. A80\%RH\&C80\%RH, A $80 \%$ RH\&C40\%RH, A40\%RH\&C $80 \%$ RH and A40\%RH\&C40\%RH were investigated. $T_{\max }-T_{\min }$ decreases with the increase in $T_{\text {init }}$, irrespective of the separator thickness.

We believe that the following heat balance equation can be considered for the whole PEMFC:

$$
Q_{\text {react }}=G_{\text {cell }} c_{\text {p,cell }}\left(T-T_{\text {init }}\right)
$$


where $Q_{\text {react }}$ indicates the heat generated from the $\mathrm{H}_{2} \mathrm{O}$ formation reaction of $\mathrm{H}_{2}$ and $\mathrm{O}_{2}$, $G_{\text {cell }}$ indicates the mass of a cell, $c_{p}$, cell indicates the specific heat of a cell and $T$ indicates the temperature of a cell elevated from $T_{\text {init }}$. Here, $Q_{\text {react }}$ indicates heat generated during power generation, whereby the PEMFC is heated by $Q_{\text {react }}$. After attaining the steady state, $T$ is fixed. When the separator thickness is small, $G_{\text {cell }}$ is small. As a result, the heat capacity comprising $G_{\text {cell }}$ and $c_{\text {p,cell }}$ becomes small.

In this study, $Q_{\text {react }}$ can be estimated from the following equation:

$$
Q_{\text {react }}=E_{\mathrm{i}}-W_{\mathrm{E}}
$$

where $E_{\mathrm{i}}$ indicates the ideal energy generation rate decided by $\mathrm{H}_{2} \mathrm{O}$ production from $\mathrm{H}_{2}$ and $\mathrm{O}_{2}$ and $W_{\mathrm{E}}$ indicates the electric power generated by PEMFC. $E_{\mathrm{i}}$ and $W_{\mathrm{E}}$ are expressed as follows:

$$
\begin{gathered}
E_{\mathrm{i}}=M_{\mathrm{H} 2} \times q \\
W_{\mathrm{E}}=I \times V
\end{gathered}
$$

Here, $I$ is kept at $20 \mathrm{~A}\left(=0.80 \mathrm{~A} / \mathrm{cm}^{2}\right) ; V$ indicates the voltage obtained by the power generation experiment; $q$ indicates the heating value for the $\mathrm{H}_{2} \mathrm{O}$ formation reaction of $\mathrm{H}_{2}$ and $\mathrm{O}_{2} ; M_{\mathrm{H} 2}$ indicates the molar flow rate of supplied $\mathrm{H}_{2}$, which is the same as the ideal reaction consumption rate of $\mathrm{H}_{2}$ required for the generation of 20 A, i.e., an s.r. of 1.0. Here, s.r. means the ratio of the feed amount of $\mathrm{H}_{2}$ and $\mathrm{O}_{2}$ required to generate a current of $20 \mathrm{~A}$. The consumption rate of supplied $\mathrm{H}_{2}$ at an s.r. of 1.0 is defined by Equation (1).

We estimated $Q_{\text {react }}$ under each power generation condition as well as $G_{\text {cell }}$ and $c_{\text {p,cell }}$ comprising the PEM, catalyst layer, MPL, GDL, separator, hot water passage plate, current collector, and end block. We also estimated $G_{\text {cell }}$ and $c_{\text {p,cell }}$ by changing the separator thickness. When considering the different separator thicknesses, we estimated the heat capacity of a solid as well as that of $\mathrm{H}_{2} \mathrm{O}$ vapor and $\mathrm{O}_{2}$ or $\mathrm{H}_{2}$ in the gas channel. We considered the following equations to compare the cell temperatures among different separator thicknesses after attaining the steady state:

$$
\begin{aligned}
& Q_{\text {react }}=\left(C_{\mathrm{p}}+C_{\mathrm{p}, \mathrm{sep}}\right) \Delta T \\
& Q_{\text {react }}^{\prime}=\left(C_{\mathrm{p}}+C_{\mathrm{p}, \mathrm{sep}}^{\prime}\right) \Delta T^{\prime} \\
& Q_{\text {react }}^{\prime \prime}=\left(C_{\mathrm{p}}+C_{\mathrm{p}, \mathrm{sep}}^{\prime \prime}\right) \Delta T^{\prime \prime}
\end{aligned}
$$

where $Q_{\text {react }}, Q^{\prime}$ react and $Q^{\prime \prime}$ react indicate the heat generated from the $\mathrm{H}_{2} \mathrm{O}$ formation reaction of $\mathrm{H}_{2}$ and $\mathrm{O}_{2}$ for separator thicknesses of $2.0 \mathrm{~mm}$ (saddle thickness: $1.0 \mathrm{~mm}$; channel height: $1.0 \mathrm{~mm}$ ), $1.5 \mathrm{~mm}$ (saddle thickness: $0.5 \mathrm{~mm}$; channel height: $1.0 \mathrm{~mm}$ ) and $1.0 \mathrm{~mm}$ (saddle height: $0.5 \mathrm{~mm}$; channel height: $0.5 \mathrm{~mm}$ ), respectively. $C_{\mathrm{p}}$ indicates the specific heat of components of cells, excluding the separator, e.g., PEM, catalyst layer, MPL, GDL, hot water passage plate, current collector and end block. $C_{p}$, sep, $C_{p \text {,sep }}^{\prime}$ and $C^{\prime \prime}$,sep indicate the specific heat of the separator for thicknesses of $2.0 \mathrm{~mm}, 1.5 \mathrm{~mm}$ and $1.0 \mathrm{~mm}$, respectively. Here, $\Delta T, \Delta T^{\prime}$ and $\Delta T^{\prime \prime}$ indicate the temperature increases in the cell from $T_{\text {init }}$ for separator thicknesses of $2.0 \mathrm{~mm}, 1.5 \mathrm{~mm}$ and $1.0 \mathrm{~mm}$, respectively. According to these equations, the following temperature increase ratio can be drawn up:

$$
\begin{aligned}
& \frac{\Delta T^{\prime}}{\Delta T}=\frac{Q_{\text {react }}^{\prime}}{Q_{\text {react }}} \frac{C_{\mathrm{p}}+C_{\mathrm{p}, \text { sep }}}{C_{\mathrm{p}}+C_{\mathrm{p} \text {,sep }}^{\prime}}=\alpha \frac{C_{\mathrm{p}}+C_{\mathrm{p}, \text { sep }}}{C_{\mathrm{p}}+C_{\mathrm{p}, \mathrm{sep}}^{\prime}} \\
& \Delta T^{\prime}=\alpha \frac{C_{\mathrm{p}}+C_{\mathrm{p}, \mathrm{sep}}}{C_{\mathrm{p}}+C_{\mathrm{p}, \mathrm{sep}}^{\prime}} \Delta T \\
& \frac{\Delta T^{\prime \prime}}{\Delta T}=\frac{Q_{\text {react }}^{\prime \prime}}{Q_{\text {react }}} \frac{C_{\mathrm{p}}+C_{\mathrm{p}, \mathrm{sep}}}{C_{\mathrm{p}}+C_{\mathrm{p}, \mathrm{sep}}^{\prime \prime}}=\beta \frac{C_{\mathrm{p}}+C_{\mathrm{p} \text {, sep }}}{C_{\mathrm{p}}+C_{\mathrm{p} \text {, sep }}^{\prime \prime}}
\end{aligned}
$$




$$
\Delta T^{\prime \prime}=\beta \frac{C_{\mathrm{p}}+C_{\mathrm{p}, \text { sep }}}{C_{\mathrm{p}}+C_{\mathrm{p}, \text { sep }}^{\prime \prime}} \Delta T
$$

After the calculation performed by inputting the physical properties and $Q_{\text {react }}, Q^{\prime}$ react and $Q^{\prime \prime}$ react into Equations (11) and (13) under each power generation condition, $\frac{\Delta T^{\prime}}{\Delta T}$ and $\frac{\Delta T^{\prime \prime}}{\Delta T}$ both measure over 1.0, irrespective of $T_{\text {init }}$ and RH conditions, e.g., $\frac{\Delta T^{\prime}}{\Delta T}$ and $\frac{\Delta T^{\prime \prime}}{\Delta T}$ at $T_{\text {init }}=363 \mathrm{~K}$ with $\mathrm{A} 40 \% \mathrm{RH} \& \mathrm{C} 40 \% \mathrm{RH}$ are 1.128 and 1.144 , respectively. In addition, $\frac{\Delta T^{\prime}}{\Delta T}$ and $\frac{\Delta T^{\prime \prime}}{\Delta T}$ increase with the increase in $T_{\text {init, }}$ e.g., $\frac{\Delta T^{\prime}}{\Delta T}$ values at $T_{\text {init }}=353 \mathrm{~K}, 363 \mathrm{~K}$ and $373 \mathrm{~K}$ with $\mathrm{A} 80 \% \mathrm{RH} \& \mathrm{C} 80 \% \mathrm{RH}$ are $1.049,1.111$ and 1.142 , respectively. Moreover, $\frac{\Delta T^{\prime}}{\Delta T}$ and $\frac{\Delta T^{\prime \prime}}{\Delta T}$ increase with the decrease in $\mathrm{RH}$ and the largest $\frac{\Delta T^{\prime}}{\Delta T}$ and $\frac{\Delta T^{\prime \prime}}{\Delta T}$ values are obtained with $\mathrm{A} 40 \% \mathrm{RH} \& \mathrm{C} 40 \% \mathrm{RH}$, e.g., $\frac{\Delta T^{\prime \prime}}{\Delta T}$ values at $T_{\text {init }}=363 \mathrm{~K}$ with $\mathrm{A} 80 \% \mathrm{RH} \& \mathrm{C} 80 \% \mathrm{RH}$ and $\mathrm{A} 40 \% \mathrm{RH} \& \mathrm{C} 40 \% \mathrm{RH}$ are 1.111 and 1.128 , respectively. As a result, it is revealed that the cell temperature increases with the decrease in separator thickness because of the decrease in heat capacity. According to these investigations, it is thought that discussion considering the heat capacity is meaningful.

The temperature drop near position $\mathrm{D}$, which is the inlet of the gas flow on the opposite side through the cell, is caused by the supply gas. The temperature at position $\mathrm{D}$ is lower than the cell temperature, causing the temperature drop $[23,28]$. Since position $\mathrm{L}$ is located in the corner part of the serpentine channel, $\mathrm{H}_{2} \mathrm{O}$ may accumulate there [34,35]. In addition, it can be thought that $\mathrm{H}_{2} \mathrm{O}$ in gas flowing through the gas channel accumulates near the outlet of the cell $[23,36]$. As a result, the gas diffusion inhibition occurs at not only position $\mathrm{L}$, but also the position near the outlet (position $\mathrm{T}$ ), which causes the temperature drop. Although $\mathrm{H}_{2} \mathrm{O}$ may accumulate along with the gas flow direction, the temperature decreases at position $\mathrm{L}$ and then increases again, as seen in Figure 10. According to the previous report [37] investigating the observations of $\mathrm{H}_{2} \mathrm{O}$ behavior in the GDL and gas channel experimentally, the cross-flow in the GDL would occur under the rib part, promoting the power generation around the area where liquid $\mathrm{H}_{2} \mathrm{O}$ is accumulated [22]. Due to this reason, the temperature increases again after position $\mathrm{L}$. The increase in concentration of the $\mathrm{H}_{2} \mathrm{O}$ vapor would decrease the partial pressure of $\mathrm{O}_{2}$ and influence the mass transfer of $\mathrm{O}_{2}$ to the catalyst layer [38], resulting in a temperature drop near the outlet of cell [23]. On the other hand, $\mathrm{H}_{2} \mathrm{O}$ is difficult to liquefy when the thinner separator is used due to smaller heat capacity and thermal resistance. The gas diffusion is inhibited by the accumulation of liquid $\mathrm{H}_{2} \mathrm{O}$ and is smaller when the thinner separator is used, meaning that PEM would is hydrated by $\mathrm{H}_{2} \mathrm{O}$ towards the end of the gas channel $[23,36]$. Therefore, the temperature increases along with the gas flow through the gas channel $[23,36]$.

According to Figures 13 and 14, it can be found that the separator thickness of $2.0 \mathrm{~mm}$ shows an odd-shaped temperature distribution, i.e., the temperature decreases at positions $\mathrm{D}, \mathrm{L}$ and T. On the other hand, the temperature increases from the inlet to the outlet for separator thicknesses of $1.5 \mathrm{~mm}$ and $1.0 \mathrm{~mm}$. Additionally, it can be observed from Figure 15 that the temperature difference $\left(T_{\max }-T_{\min }\right)$ decreases with the increase in $T_{\text {init }}$, irrespective of the separator thickness. As shown in Table 2, the temperature was measured by thermography at the current density of $0.80 \mathrm{~A} / \mathrm{cm}^{2}$ in this study. According to Figures $4-8$, the voltage decreases with the increase in $T_{\text {init }}$, especially at high current densities such as $0.80 \mathrm{~A} / \mathrm{cm}^{2}$, irrespective of the separator thickness. An experimental and numerical study on the relationship between temperature distribution and power generation characteristics using a micro-temperature sensor installed on the interface between the GDL and gas separator at the cathode and computer fluid analysis (CFD) reported that the temperature was higher at the high current density, indicating good power generation performance [39]. In addition, it was reported that the hydrated condition caused the wider temperature distribution [39]. Since the power generation performance at higher temperatures is lower due to dehydration, as shown in Figures 4-8, the in-plane temperature distribution becomes more even.

Figures 16-18 show a comparison of in-plane temperature distributions at cathode side among different RHs and $T_{\text {init }}$ values for the separator thicknesses of $2.0 \mathrm{~mm}, 1.5 \mathrm{~mm}$ 
and $1.0 \mathrm{~mm}$, respectively. A80\%RH\&C80\%RH, A80\%RH\&C40\%RH, A40\%RH\&C80\%RH and $\mathrm{A} 40 \% \mathrm{RH} \& \mathrm{C} 40 \% \mathrm{RH}$ were investigated. The $T_{\text {init }}$ values changed by $353 \mathrm{~K}, 363 \mathrm{~K}$ and $373 \mathrm{~K}$. The effect of the s.r. of the supply gas on the in-plane temperature distribution was not confirmed, meaning that this paper shows the results obtained in for an s.r. of 1.5. Regarding the in-plane temperature distribution, the error level of the data was below 3\% under every experimental conditions. To highlight the effects of the separator thickness, Figures 19 and 20 show the in-plane temperature distributions among different separator thicknesses and $T_{\text {init }}$ values with $\mathrm{A} 80 \% \mathrm{RH} \& \mathrm{C} 80 \% \mathrm{RH}$ and $\mathrm{A} 40 \% \mathrm{RH} \& \mathrm{C} 40 \% \mathrm{RH}$, respectively. A $80 \%$ RH\&C $80 \%$ RH and A40\%RH\&C40\%RH were selected as well-humidified and dry conditions, respectively. In addition, the relationship between the maximum temperature difference $\left(T_{\max }-T_{\min }\right)$ and $T_{\text {init }}$ is also shown in Figure 21.

According to Figures 16-18, it can be obviously found that the temperature decreases at positions D, L and T for the separator thickness of $2.0 \mathrm{~mm}$. On the other hand, it can be seen that the temperature increases from the inlet to the outlet gradually for the separator thicknesses of $1.5 \mathrm{~mm}$ and $1.0 \mathrm{~mm}$. Regarding the temperature drops at positions $\mathrm{D}, \mathrm{L}$ and $\mathrm{T}$, this phenomenon occurs for the same reason as at the anode side. The temperature drop in the position $\mathrm{D}$ is larger compared to the anode side. As discussed above, position $\mathrm{D}$ is the inlet of the gas flow on the opposite side through the cell, and the temperature of the supply gas is colder than the cell temperature, meaning that the temperature drops $[23,28]$. The thermal conductivity of $\mathrm{H}_{2}$, which flows through the gas channel on the opposite side, is larger than that of $\mathrm{O}_{2}$, meaning that temperature drop might be larger. Comparing the inplane temperature distribution for the thinnest separator thickness of $1.0 \mathrm{~mm}$ with different $T_{\text {init }}$ values, the temperature decreases with the increase in $T_{\text {init }}$. The temperature increase might be caused by the smaller heat capacity and thermal resistance [26], meaning that PEM and the catalyst layer are easily dehydrated. As $\mathrm{H}_{2} \mathrm{O}$ is produced by the $\mathrm{O}_{2}$ reduction reaction at the cathode side, the temperature increase from the inlet to the outlet is larger at $T_{\text {init }}=353 \mathrm{~K}$ due to balancing of the humidification of the PEM and catalyst layer with heating caused by the thinnest separator. On the other hand, at $T_{\text {init }}=363 \mathrm{~K}$ and $373 \mathrm{~K}$, it is thought that the dehydration progresses better due to the smaller heat capacity and thermal resistance [26] of the thinner separator thickness. The power generation performance at higher temperatures is lower than that at lower temperatures, as shown in Figure 6, due to dehydration. Therefore, the in-plane temperature distribution becomes more even with the increase in $T_{\text {init }}$ for the separator thickness of $1.0 \mathrm{~mm}$. Although this tendency is not remarkable in the case of separator thickness of $1.5 \mathrm{~mm}$, we think that the balance of the dehydration with the $\mathrm{H}_{2} \mathrm{O}$ produced from the $\mathrm{O}_{2}$ reduction reaction might influence this.

According to Figures 19 and 20, it can be seen that the separator thickness of $2.0 \mathrm{~mm}$ shows an odd-shaped temperature distribution, i.e., the temperature decreases at positions $\mathrm{D}, \mathrm{L}$ and T. On the other hand, the temperature increases from the inlet to the outlet for separator thicknesses of $1.5 \mathrm{~mm}$ and $1.0 \mathrm{~mm}$. Additionally, it can be observed from Figure 21 that the temperature difference $\left(T_{\max }-T_{\min }\right)$ decreases with the increase in $T_{\text {init }}$ in the case of the separator thickness of $1.0 \mathrm{~mm}$, which is the thinnest separator, indicating that the in-plane temperature distribution becomes more uniform.

Considering the above results and discussion, the following effects can be emphasized under higher temperature conditions:

(i) The decrease in separator thickness causes the power generation performance to decline according to the investigation on the heat balance, considering the heat capacity of cell components;

(ii) The drying impact due to the decrease in separator thickness and the low-humidity gas supply is significant for the power generation performance and temperature distribution; 
(a) $-\mathrm{A} 80 \% \mathrm{RH}, \mathrm{C} 80 \% \mathrm{RH}-\mathrm{A} 80 \% \mathrm{RH}, \mathrm{C} 40 \% \mathrm{RH}$
$-\mathrm{A} 40 \% \mathrm{RH}, \mathrm{C} 80 \% \mathrm{RH}-\mathrm{A} 40 \% \mathrm{RH}, \mathrm{C} 40 \% \mathrm{RH}$

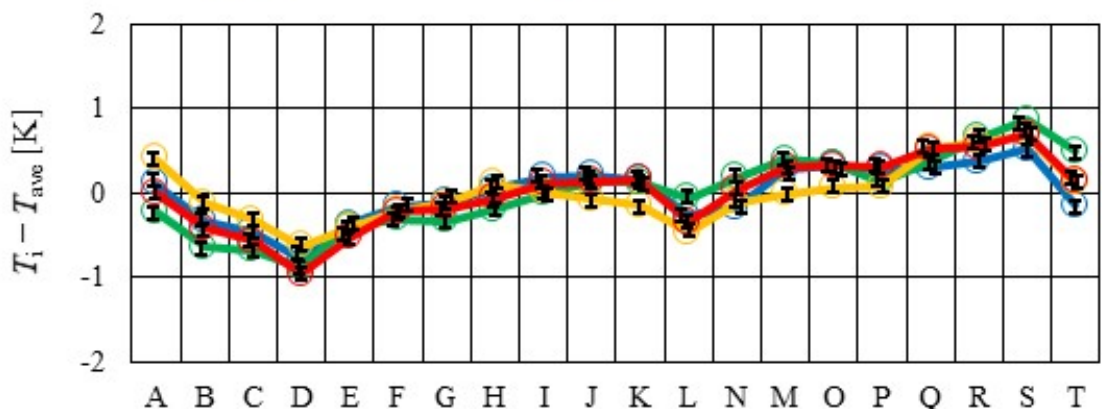

Position

(b)

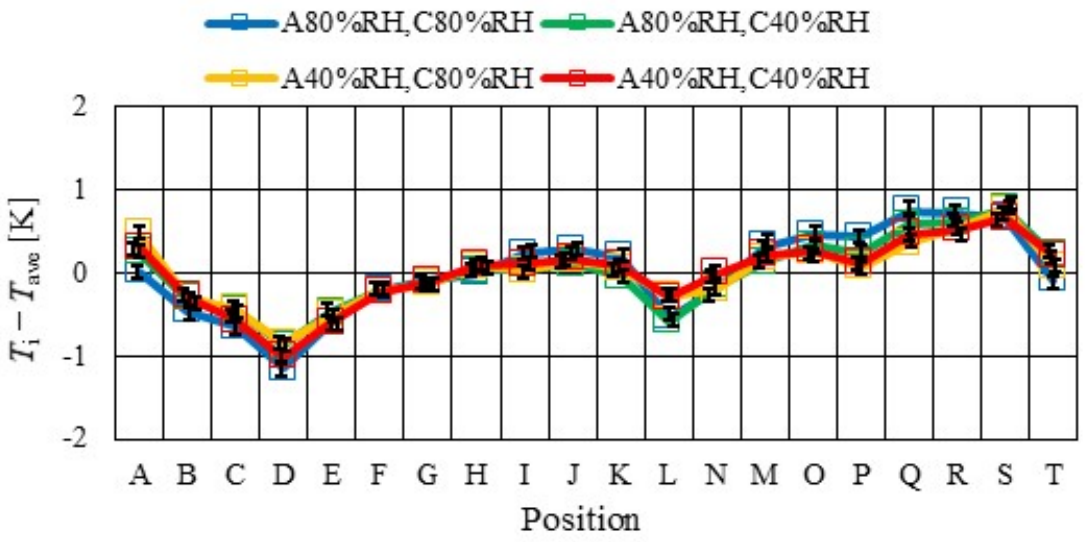

(c)

$-\mathrm{A} 80 \% \mathrm{RH}, \mathrm{C} 80 \% \mathrm{RH}=\mathrm{A} 80 \% \mathrm{RH}, \mathrm{C} 40 \% \mathrm{RH}$

$-\mathrm{A} 40 \% \mathrm{RH}, \mathrm{C} 80 \% \mathrm{RH}=\mathrm{A} 40 \% \mathrm{RH}, \mathrm{C} 40 \% \mathrm{RH}$

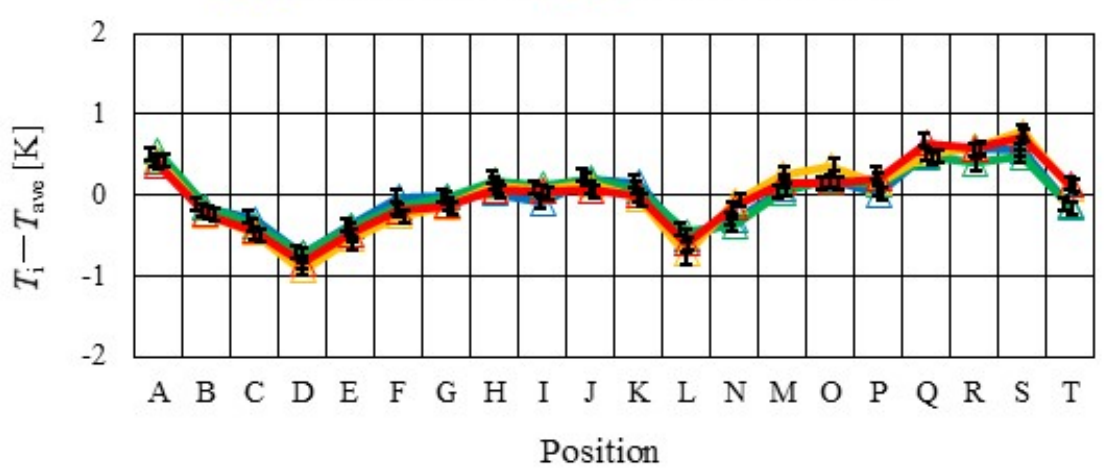

Figure 16. Comparison of in-plane temperature distributions at the cathode side among different RHs in the case of the separator thickness of $2.0 \mathrm{~mm}$ : (a) $T_{\text {init }}=353 \mathrm{~K}$; (b) $T_{\text {init }}=363 \mathrm{~K}$; (c) $T_{\text {init }}=373 \mathrm{~K}$. 
(a)
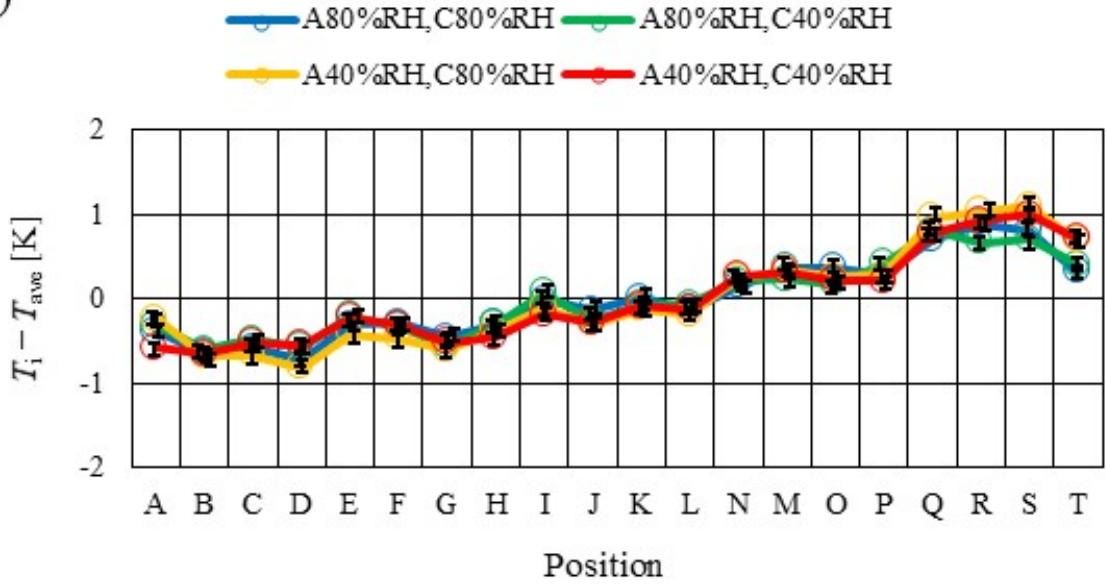

(b)

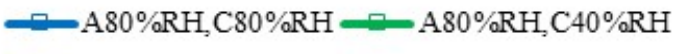

$-\mathrm{A} 40 \% \mathrm{RH}, \mathrm{C} 80 \% \mathrm{RH}=\mathrm{A} 40 \% \mathrm{RH}, \mathrm{C} 40 \% \mathrm{RH}$

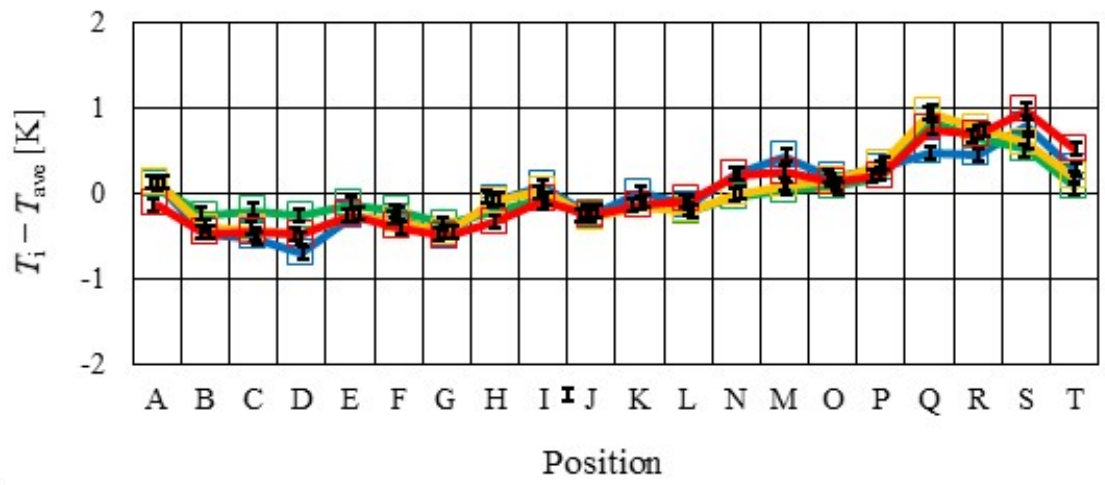

(c)

$\simeq \mathrm{A} 80 \% \mathrm{RH}, \mathrm{C} 80 \% \mathrm{RH}=\mathrm{A} 80 \% \mathrm{RH}, \mathrm{C} 40 \% \mathrm{RH}$

$\longrightarrow \mathrm{A} 40 \% \mathrm{RH}, \mathrm{C} 80 \% \mathrm{RH}=\mathrm{A} 40 \% \mathrm{RH}, \mathrm{C} 40 \% \mathrm{RH}$

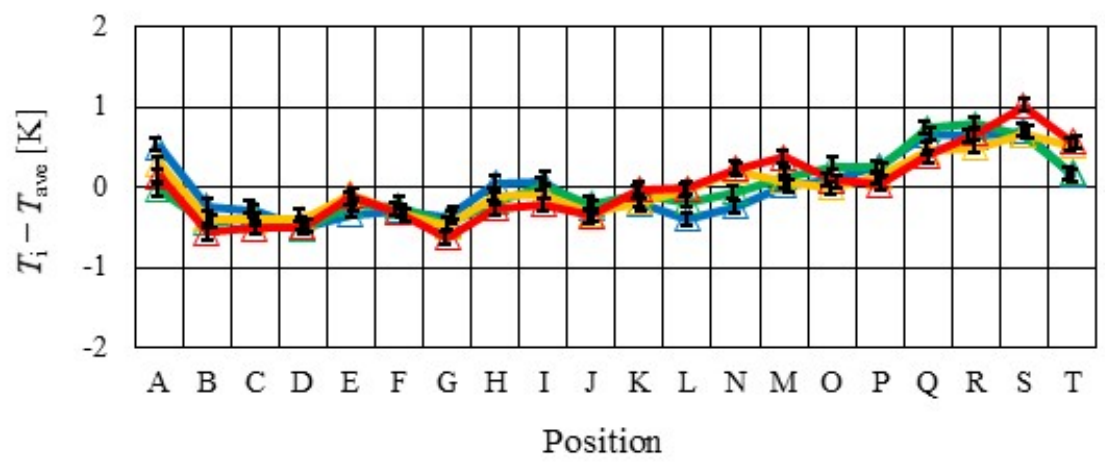

Figure 17. Comparison of in-plane temperature distributions at the cathode side among different RHs in the case of the separator thickness of $1.5 \mathrm{~mm}$ : (a) $T_{\text {init }}=353 \mathrm{~K}$; (b) $T_{\text {init }}=363 \mathrm{~K}$; (c) $T_{\text {init }}=373 \mathrm{~K}$. A $80 \%$ RH\&C $80 \%$ RH, A $80 \%$ RH\&C40\%RH, A40\%RH\&C $80 \%$ RH and A40\%RH\&C40\%RH were investigated. The temperature increases from the inlet to the outlet gradually. 
(a)
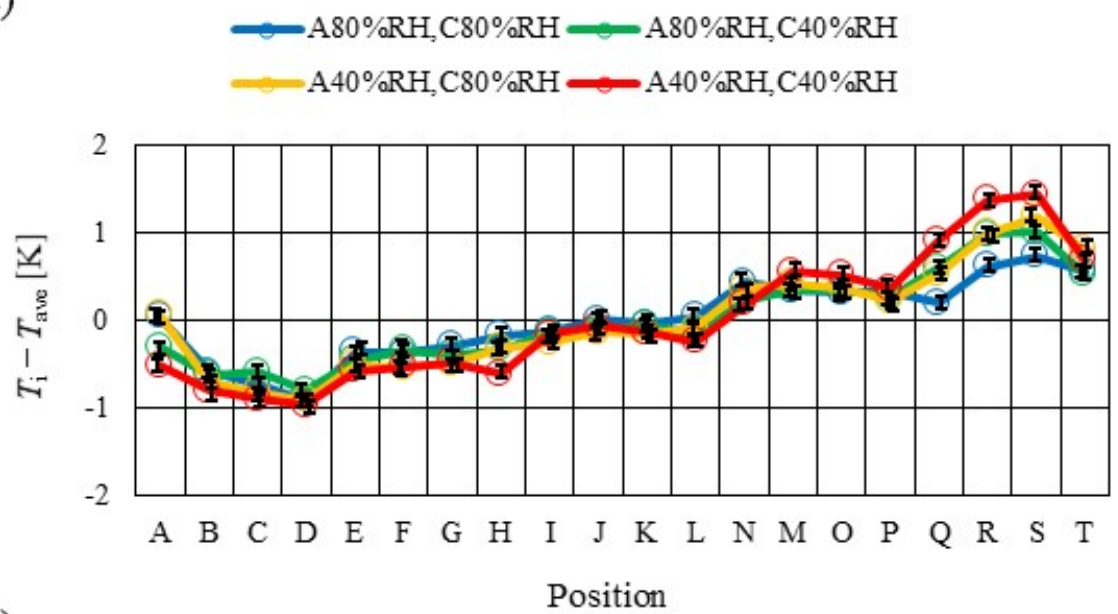

(b)

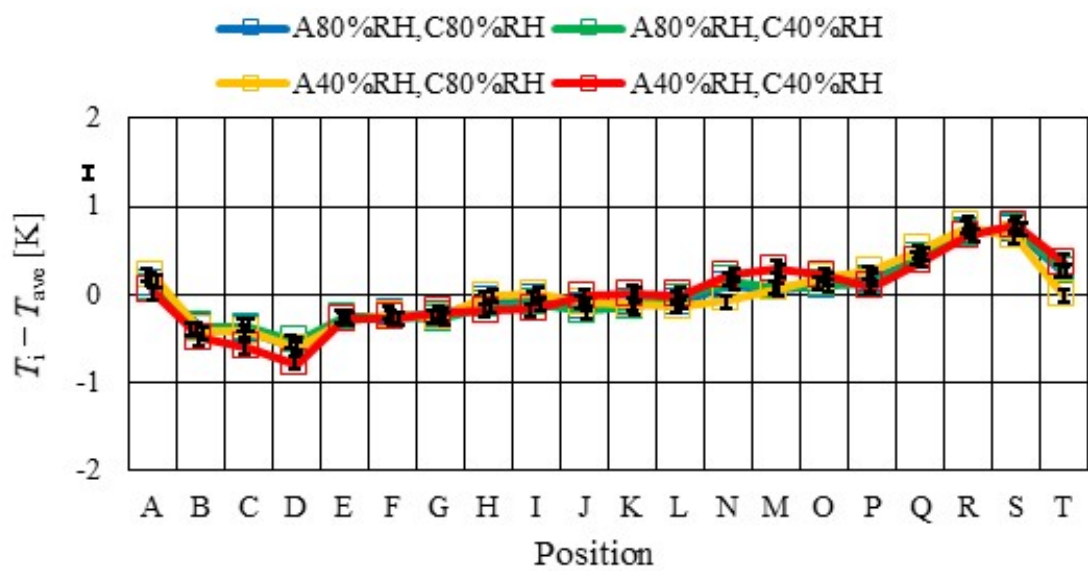

(c)

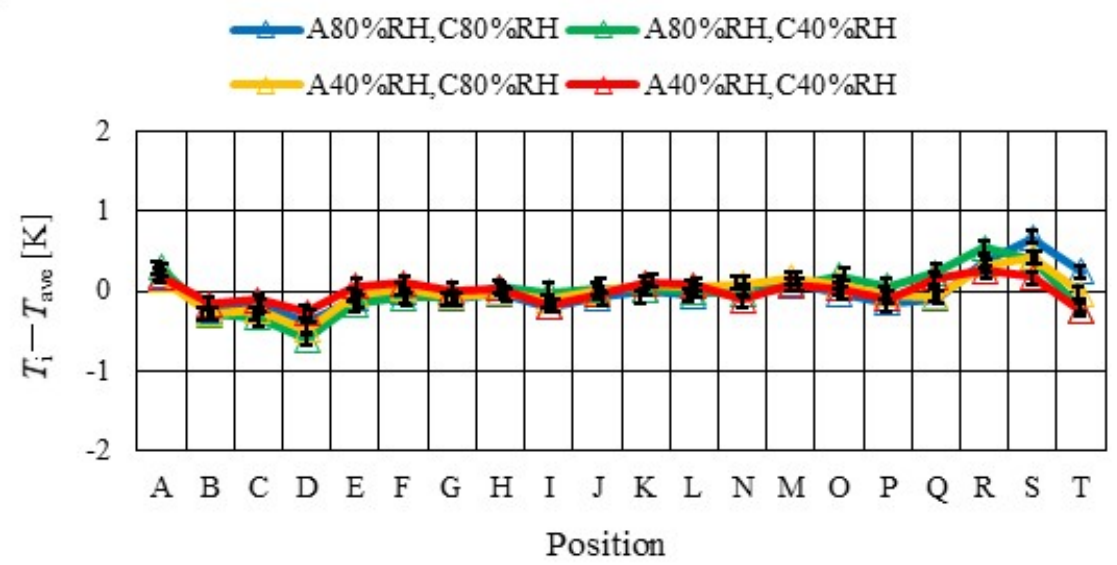

Figure 18. Comparison of in-plane temperature distributions at the cathode side among different RHs in the case of the separator thickness of $1.0 \mathrm{~mm}$ : (a) $T_{\text {init }}=353 \mathrm{~K}$; (b) $T_{\text {init }}=363 \mathrm{~K}$; (c) $T_{\text {init }}=373 \mathrm{~K}$. 
(a)

$\multimap \mathrm{Sa}: 1.0 \mathrm{~mm}, \mathrm{Ch}: 1.0 \mathrm{~mm}$

$\square \mathrm{Sa}: 0.5 \mathrm{~mm}, \mathrm{Ch}: 1.0 \mathrm{~mm}$

$\triangle \mathrm{Sa}: 0.5 \mathrm{~mm}, \mathrm{Ch}: 0.5 \mathrm{~mm}$

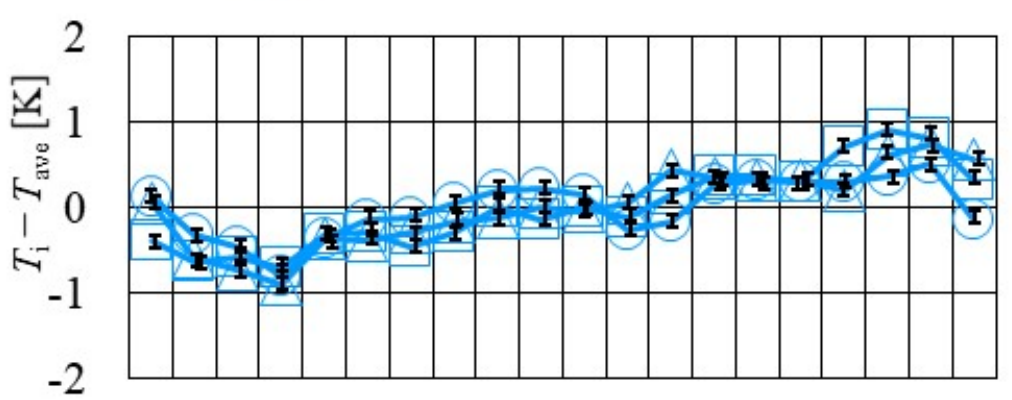

A B C D E F G H I J J K L NMOP Q R S T

(b)

$\frown \mathrm{Sa}: 1.0 \mathrm{~mm}, \mathrm{Ch}: 1.0 \mathrm{~mm}$

$\square \mathrm{Sa}: 0.5 \mathrm{~mm}, \mathrm{Ch}: 1.0 \mathrm{~mm}$

$\triangle \mathrm{Sa}: 0.5 \mathrm{~mm}, \mathrm{Ch}: 0.5 \mathrm{~mm}$

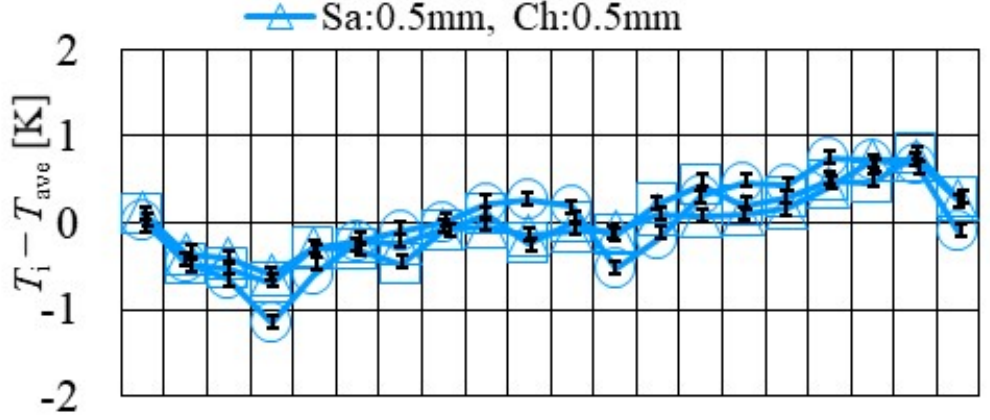

A B C D E F G I J K L NMOP Q R S T Position

(c)
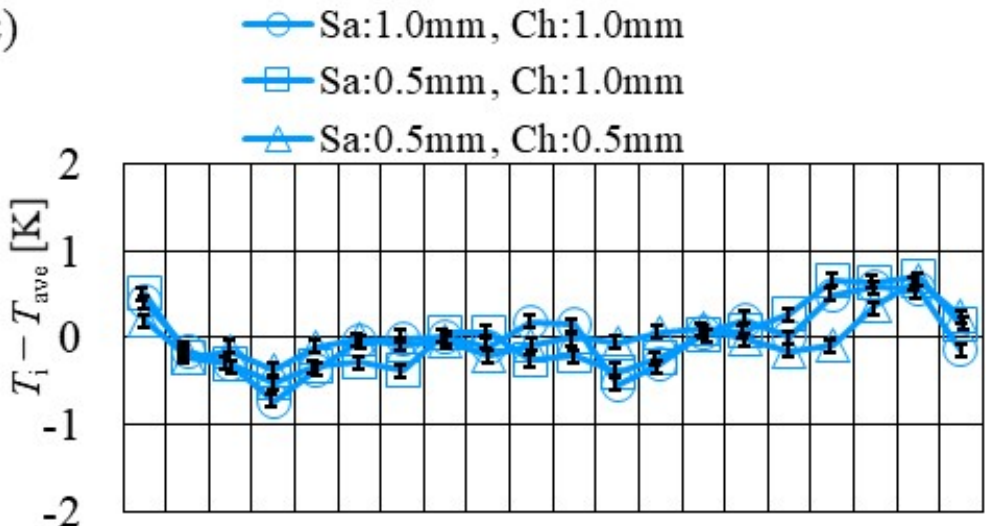

A B C D E F G H I K L NMO P Q R S T Position

Figure 19. Comparison of in-plane temperature distributions at the cathode side among different separator thicknesses with A80\%RH\&C80\%RH: (a) $T_{\text {init }}=353 \mathrm{~K}$; (b) $T_{\text {init }}=363 \mathrm{~K}$; (c) $T_{\text {init }}=373 \mathrm{~K}$. 
(a)

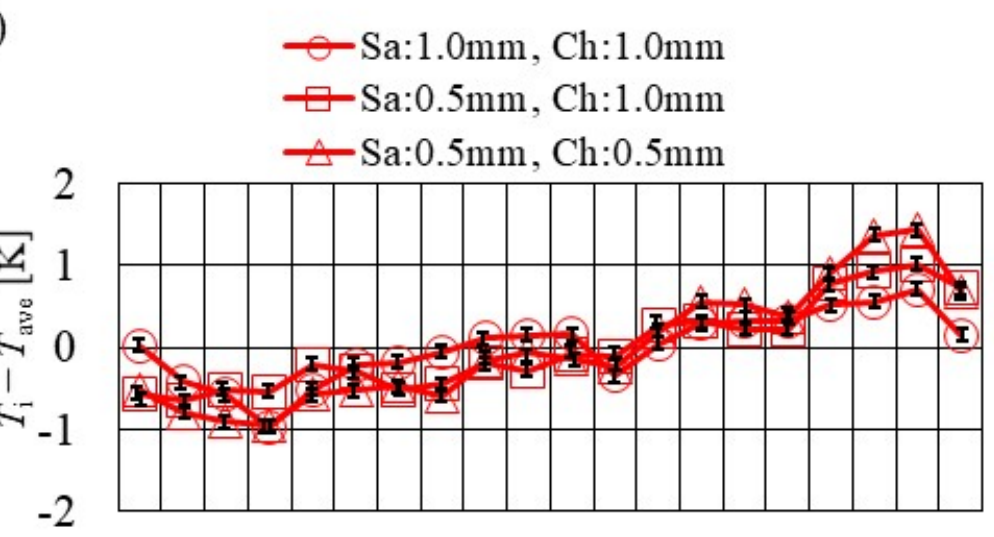

A B C D E F GH I J K L NMO P Q R T Position

(b)

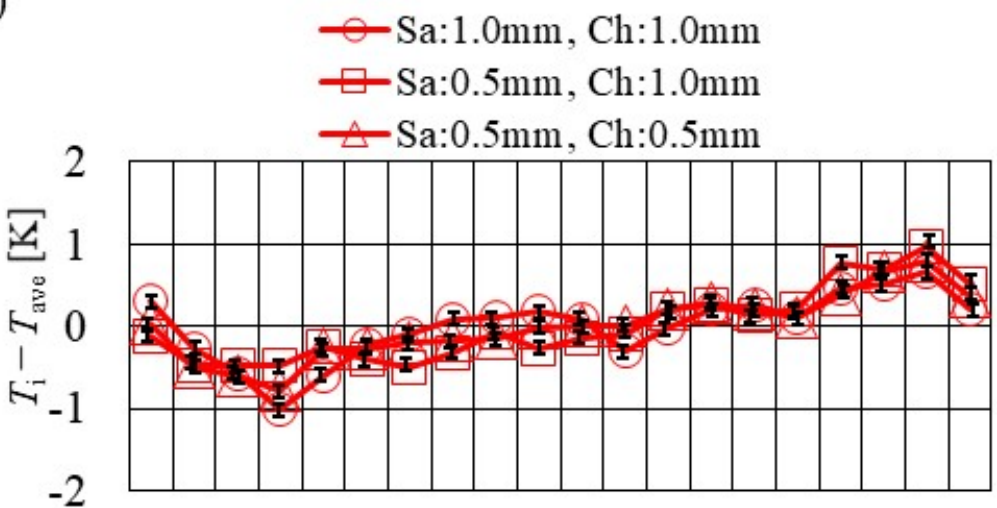

A B C DE F G I J K L NMOP Q R T Position

(c)

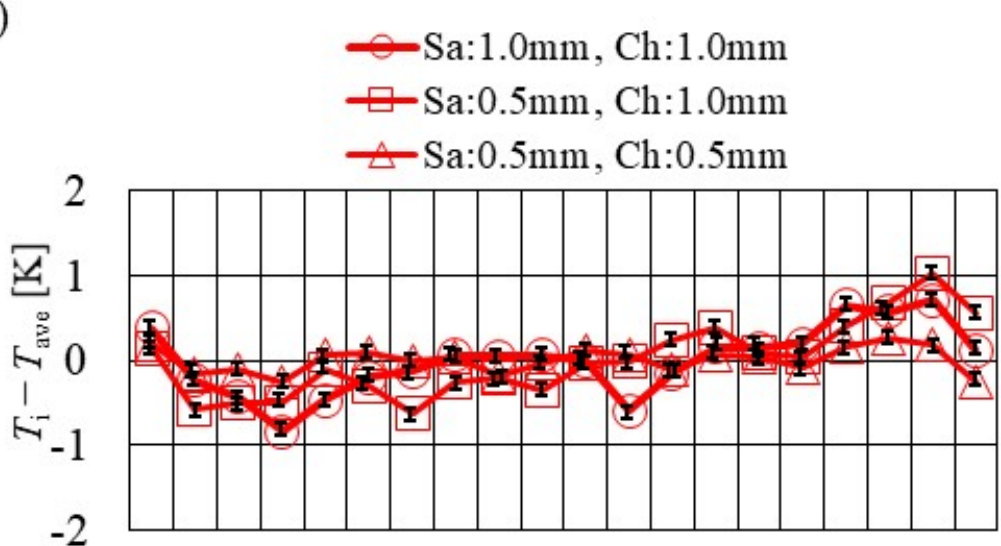

A B C D E F G H I J K L NMO P Q R S T Position

Figure 20. Comparison of in-plane temperature distributions at the cathode side among different separator thicknesses with A40\%RH\&C40\%RH: (a) $T_{\text {init }}=353 \mathrm{~K}$; (b) $T_{\text {init }}=363 \mathrm{~K}$; (c) $T_{\text {init }}=373 \mathrm{~K}$. 
(a)
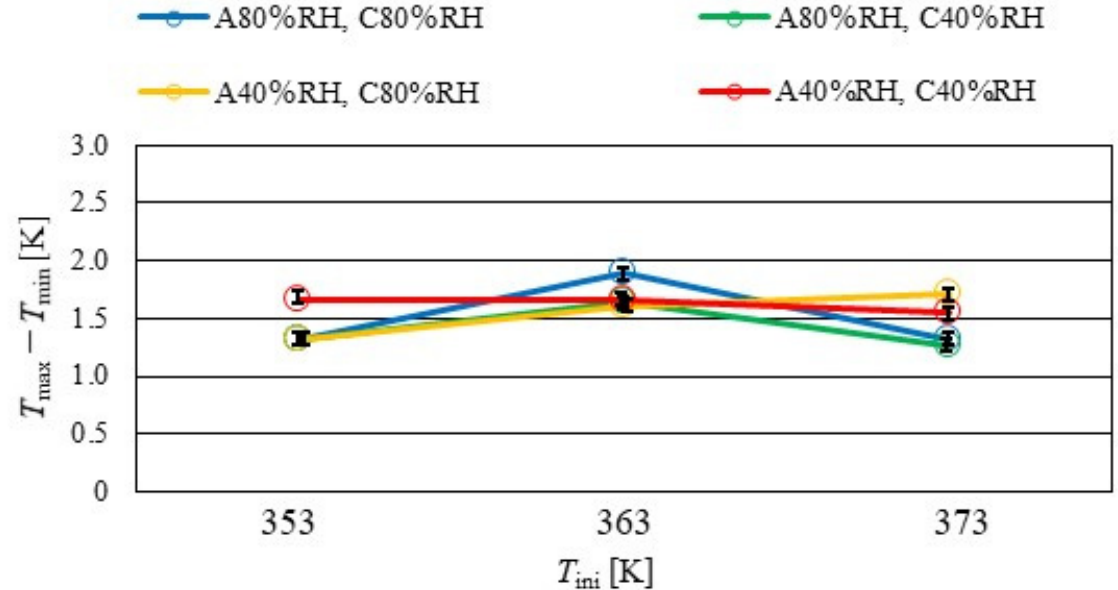

(b)

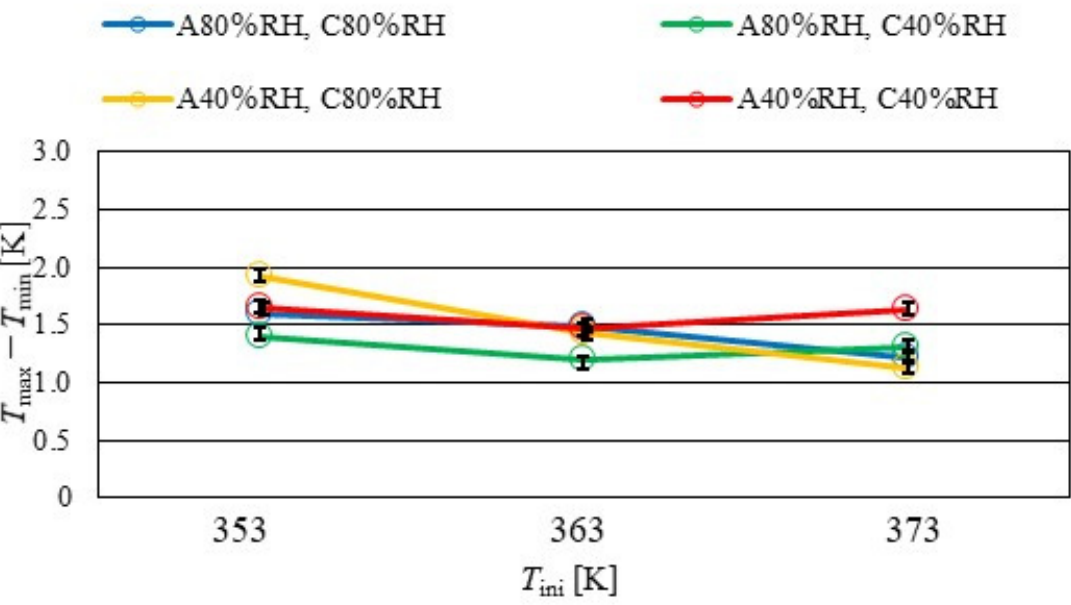

(c)

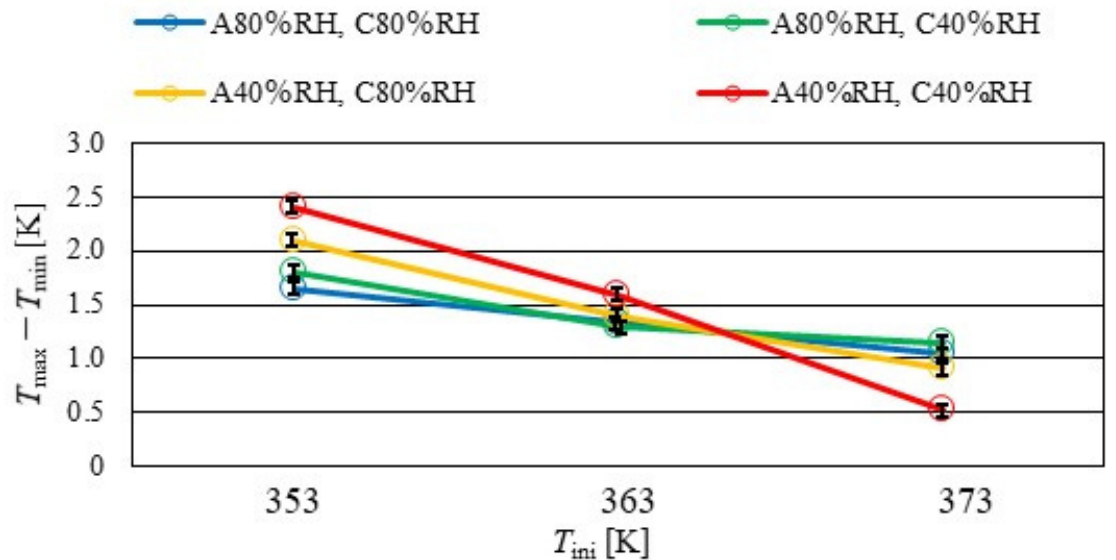

Figure 21. Comparison of relationships between the $T_{\text {init }}$ and temperature difference $T_{\max }-T_{\min }$ at the cathode side among different RHs: (a) $2.0 \mathrm{~mm}$; (b) $1.5 \mathrm{~mm}$; (c) $1.0 \mathrm{~mm}$.

According to this study, we can suggest that thin separators such as those with thicknesses of $1.5 \mathrm{~mm}$ and $1.0 \mathrm{~mm}$ are not suitable for higher temperature operations. Since humidification control at higher temperatures is harder than at usual operation temperatures, the thermal properties of cell components of PEMFC should be considered in addition to the hydration of the supply gas. According to recent review papers on the research and development of gas separators [40-43], the material type, composite and surface coating process have all been investigated to improve the conductivity and $\mathrm{H}_{2} \mathrm{O}$ 
behavior control. However, the thermal properties of separators have not been investigated. Therefore, we suggest that the thermal properties such as the heat capacity and thermal conductivity should be improved to attain high power generation performance.

In addition, in this study we used a thin PEM (Nafion membrane), which is usually used at temperature lowers than $343 \mathrm{~K}$. The degradation of Nafion membranes operated at higher temperatures should be considered. This study conducted the experimental investigation using a thin Nafion membrane at higher temperatures of $363 \mathrm{~K}$ and $373 \mathrm{~K}$ [23]. In this experiment, it was confirmed that the thin Nafion membrane could maintain the performance over the power generation operation rate of $200 \mathrm{~h}$. However, it is necessary to study the characteristics of thin Nafion membranes operated for longer operation times, e.g., $90,000 \mathrm{~h}$ (=10 years), which is the target operation time according to the NEDO Road Map 2010 in Japan [44], for the practical application of PEMFC systems.

\section{Conclusions}

In this study, we investigated the effect of the separator thickness on not only the heat and mass transfer characteristics but also the power generation characteristics of PEMFC systems using the combination of a thin PEM and thin GDL operated at higher temperatures, such as $363 \mathrm{~K}$ and $373 \mathrm{~K}$. The in-plane temperature distributions on the back of the separator at the anode and cathode were measured using a thermograph, changing the $T_{\text {init }}, \mathrm{RH}$ and flow rates of the supply gases. The total voltage and load current have been measured and analyzed in order to evaluate the performance of the PEMFC. The conclusions have been obtained as follows:

(i) It was revealed that the effect of RH on the power generation performance increases with the decrease in separator thickness. The power generation performance with A $40 \%$ RH\&C40\%RH drops rapidly with the decrease in separator thickness;

(ii) It was revealed that the power generation performance at high current densities decreases with the increase in $T_{\text {init }}$ with thinner separator thicknesses;

(iii) Regarding the anode observations, it was confirmed that the temperature drops at corner positions in the separator, such as positions D, L and T, with the separator thickness of $2.0 \mathrm{~mm}$. On the other hand, it was confirmed that the temperature increased from the inlet to the outlet by approximately $2 \mathrm{~K}$ gradually for the separator thicknesses of $1.5 \mathrm{~mm}$ and $1.0 \mathrm{~mm}$;

(iv) Regarding the anode observations, $T_{\max }-T_{\min }$ decreases with the increase in $T_{\text {init }}$ irrespective of the separator thickness because of the lower power generation performance;

(v) Regarding cathode observations, it was confirmed that the temperature deceases at corner positions in the separator, such as positions D, L and T, with the separator thickness of $2.0 \mathrm{~mm}$, while the temperature increases from the inlet to the outlet gradually with the separator thicknesses of $1.5 \mathrm{~mm}$ and $1.0 \mathrm{~mm}$. The temperature drop at position $\mathrm{D}$ is larger compared to the anode side, since the thermal conductivity of $\mathrm{H}_{2}$, which flows through the gas channel on the opposite side, is larger than that of $\mathrm{O}_{2}$. It was revealed that the temperature difference $T_{\max }-T_{\min }$ is smaller, indicating that the in-plane temperature distribution becomes more even with the increase in $T_{\text {init }}$ in the case of the separator thickness of $1.0 \mathrm{~mm}$;

(vi) The decrease in separator thickness causes the power generation performance to decline according to the investigation on the heat balance, considering the heat capacity of cell components;

(vii) The drying impact due to the decrease in separator thickness as well as the lowhumidity gas supply is significant for the power generation performance and temperature distribution. 
Author Contributions: Conceptualization, funding acquisition and writing-original draft preparation, A.N.; experimentation and data curation, Y.K. and S.I.; writing-review and editing, E.H. All authors have read and agreed to the published version of the manuscript.

Funding: This research has received funding from Mie University.

Institutional Review Board Statement: Not applicable.

Informed Consent Statement: Not applicable.

Data Availability Statement: Data presented in this paper are publicly available.

Conflicts of Interest: The authors declare no conflict of interest.

\section{Abbreviations}

$C_{\mathrm{p}} \quad$ Specific heat of components of the cell excluding the separator, e.g., PEM, catalyst layer, MPL, GDL, hot water passage plate, current collector and end block

$c_{\mathrm{p}, \text { cell }} \quad$ Specific heat of the cell

$C_{\mathrm{p} \text {,sep }} \quad$ Specific heat of the separator for thickness in the case of $2.0 \mathrm{~mm}$

$C^{\prime}$ p,sep Specific heat of the separator for thickness in the case of $1.5 \mathrm{~mm}$

$C^{\prime \prime}$,sep Specific heat of the separator for thickness in the case of $1.0 \mathrm{~mm}$

$E_{\mathrm{i}} \quad$ Ideal energy generation rate by $\mathrm{H}_{2} \mathrm{O}$ formation from $\mathrm{H}_{2}$ and $\mathrm{O}_{2}$

F $\quad$ Faraday constant

$G_{\text {cell }} \quad$ Mass of the cell

I Load current

$M_{\mathrm{H} 2} \quad$ Molar flow rate of $\mathrm{H}_{2}$

$\mathrm{M}_{\mathrm{O} 2} \quad$ Molar flow rate of $\mathrm{O}_{2}$

n Valence ion

$q \quad$ Heating value for the $\mathrm{H}_{2} \mathrm{O}$ formation reaction of $\mathrm{H}_{2}$ and $\mathrm{O}_{2}$

$Q_{\text {react }} \quad$ Heat generated from the $\mathrm{H}_{2} \mathrm{O}$ formation reaction of $\mathrm{H}_{2}$ and $\mathrm{O}_{2}$ for separator thickness of $2.0 \mathrm{~mm}$

$Q^{\prime}$ react Heat generated from the $\mathrm{H}_{2} \mathrm{O}$ formation reaction of $\mathrm{H}_{2}$ and $\mathrm{O}_{2}$ for separator thickness of $1.5 \mathrm{~mm}$

$Q^{\prime \prime}$ react Heat generated from the $\mathrm{H}_{2} \mathrm{O}$ formation reaction of $\mathrm{H}_{2}$ and $\mathrm{O}_{2}$ in case of separator thickness of $1.0 \mathrm{~mm}$

$T \quad$ Temperature of cell elevated from the initial temperature

$T_{\mathrm{i}} \quad$ Average temperature in respective areas from $\mathrm{A}$ to $\mathrm{T}$

$T_{\text {ave }} \quad$ Average temperature among all areas from $\mathrm{A}$ to $\mathrm{T}$

$T_{\text {init }} \quad$ Initial temperature of cell

$T_{\max } \quad$ Maximum temperature among the temperatures of locations from $\mathrm{A}$ to $\mathrm{T}$

$T_{\min } \quad$ Minimum temperature among the temperatures of locations from A to $\mathrm{T}$

$V \quad$ Voltage obtained from the power generation experiment

$W_{\mathrm{E}} \quad$ Electric power generated by PEMFC

$\alpha \quad Q^{\prime}$ react $/ Q_{\text {react }}$

$\beta \quad Q^{\prime \prime}$ react $/ Q_{\text {react }}$

$\Delta T \quad$ Temperature increase in the cell from the initial temperature for separator thickness of $2.0 \mathrm{~mm}$

$\Delta T^{\prime} \quad$ Temperature increase in the cell from the initial temperature for separator thickness of $1.5 \mathrm{~mm}$

$\Delta T^{\prime \prime} \quad$ Temperature increase in the cell from the initial temperature for separator thickness of $1.0 \mathrm{~mm}$

\section{References}

1. New Energy and Industry Technology Development Organization (NEDO). Available online: http://www.nedo.go.jp/cotent/10 0871973 (accessed on 1 November 2021). (In Japanese)

2. Li, Q.; He, R.; Jensen, J.O.; Bjerrum, N.J. Approaches and recent development polymer electrolyte membrane for fuel cells operating above $100^{\circ} \mathrm{C}$. Chem. Mater. 2003, 15, 4896-4915. [CrossRef]

3. Zhang, G.; Kandlikar, S.G.A. Critical review of cooling technique in proton exchange membrane fuel cell stacks. Int. J. Hydrogen Energy 2012, 37, 2412-2429. [CrossRef]

4. Agbossou, K.; Kolhe, M.; Hamelin, J.; Bose, T.K. Performance of a stand-alone renewable energy system based on energy storage as hydrogen. IEEE Trans. Energy Convers. 2004, 19, 633-640. [CrossRef] 
5. Zhang, J.; Zhang, C.; Hao, D.; Ni, M.; Huang, S.; Liu, D.; Zheng, Y. 3D Non-isothermal dynamic simulation of high temperature proton exchange membrane fuel cell in the start-up process. Int. J. Hydrogen Energy 2021, 46, 2577-2593. [CrossRef]

6. Lee, C.Y.; Wng, F.; Kuo, Y.W.; Tsai, C.H.; Cheng, Y.T.; Cheng, C.K.; Lin, J.T. In-situ measurement of high-temperature proton exchange membrane fuel cell stack using flexible five-in-one micro sensor. Sensors 2016, 16, 1731. [CrossRef] [PubMed]

7. Budak, Y.; Devrim, Y. Micro-cogeneration application of a high-temperature PEM fuel cell stack operated with polybenzimidazole based membranes. Int. J. Hydrogen Energy 2020, 45, 35198-35207. [CrossRef]

8. Kim, D.H.; Min, C.M.; Lee, E.; Lee, J.S.; Pak, C. Effect of vinylphosphonic acid and polymer binders with phospate groups on performance of high-temperature polymer electrolyte membrane fuel cell. Catal. Today 2020, 358, 333-337. [CrossRef]

9. Lee, W.J.; Lee, J.S.; Park, H.Y.; Park, H.S.; Lee, S.Y.; Song, K.H.; Kim, H.J. Improvement of fuel cell performances through the enhanced dispersion of the PTFE binder in electrodes for use in high temperature polymer electrolyte membrane fuel cells. Int. J. Hydrogen Energy 2020, 45, 32825-32833. [CrossRef]

10. Sasiwimonrit, K.; Chang, W.C. To Improve the high temperature polymer electrolyte membrane fuel cells performance by altering the properties of catalyst layer. Int. J. Hydrogen Energy 2020, 45, 14491-14499. [CrossRef]

11. Wang, D.; Wang, S.; Tina, X.; Li, J.; Liu, F.; Wang, X.; Chen, H.; Mao, T.; Liu, G. Ethyl phosphoric acid grafted amino-modified polybenzimidazole with improved long-term stability for high-temperature proton exchange membrane applications. Int. J. Hydrogen Energy 2020, 45, 3176-3185. [CrossRef]

12. Kannan, A.; Kaczeriwski, J.; Kabza, A.; Sholta, J. Operation strategies based on carbon corrosion and lifetime investigations for high temperature polymer electrolyte membrane fuel cell stacks. Fuel Cells 2018, 3, 287-298. [CrossRef]

13. Quartarone, E.; Angioni, S.; Mustarelli, P. Polymer and composite membranes for proton-conducting, high-temperature fuel cells: A critical review. Materials 2021, 10, 687. [CrossRef] [PubMed]

14. Zhang, T.; Li, J.; Li, Q.; Yu, M.; Sun, H. Combination effects of flow filed structure and assembly force on performance of high temperature proton exchange membrane fuel cells. Int. J. Energy Res. 2021, 45, 7903-7917. [CrossRef]

15. Zhu, G.; Chen, W.; Lu, S.; Chen, X. Parameter study of high-temperature proton exchange membrane fuel cell using data-driven models. Int. J. Hydrogen Energy 2019, 44, 28958-28967. [CrossRef]

16. Lakshmi, B.; Harikrishnan, N.P.; Juliet, A.V. Comparative analysis of 2D and 3D model of a PEMFC in COMSOL. Appl. Surf. Sci. 2017, 418, 99-102. [CrossRef]

17. Rasheed, R.K.A.; Liao, Q.; Caizhi, Z.; Chan, S.H. A Review on modeling of high temperature proton exchange membrane fuel cells (HT-PEMFCs). Int. J. Hydrogen Energy 2017, 42, 3142-3165. [CrossRef]

18. Li, R.; Cai, Y.; Wippermann, K.; Lehnert, W. Bilayer CrN/Cr Coating-modified 316L stainless steel bipolar plates for high temperature polymer electrolyte fuel cells. J. Power Sources 2019, 434, 226718. [CrossRef]

19. Chen, C.Y.; Su, S.C. Development and performance evaluation of a high temperature proton exchange membrane fuel cell with stamped 304 stainless steel bipolar plates. Int. J. Hydrogen Energy 2018, 4, 13430-13439. [CrossRef]

20. Akitomo, F.; Sasabe, T.; Yoshida, T.; Naito, H.; Kawamura, K.; Hirai, S. Investigation of effects of high temperature and pressure on a polymer electrolyte fuel cell with polarization analysis and X-ray imaging of liquid water. J. Power Sources 2019, 431, 205-209. [CrossRef]

21. Rasheed, R.K.A.; Chan, S.H. Analysis of steady state heating configuration for high-temperature proton exchange membrane fuel cell based on multi-physical numerical modeling. Electrochim. Acta 2016, 222, 280-292. [CrossRef]

22. Nishimura, A.; Okado, T.; Kojima, Y.; Hu, E. Impact of microporous layer on heat and mass transfer in a single cell of polymer electrolyte fuel cell using a thin polymer electrolyte membrane and a thin gas diffusion layer operated at a high-temperature range. ACS OMEGA 2021, 6, 14575-14584. [CrossRef] [PubMed]

23. Nishimura, A.; Okado, T.; Kojima, Y.; Hirota, M.; Hu, E. Impact of MPL on temperature distribution in single polymer electrolyte fuel cell with various thickness of polymer electrolyte membrane. Energies 2020, 13, 2499. [CrossRef]

24. Nishimura, A.; Kono, N.; Toyoda, K.; Kojima, Y.; Kolhe, M.L. Impact analysis of MPL on a PEFC cell's temperature distribution with thin PEM and GDL for operating at higher temperature than usual. J. Energy Power Eng. 2021, 15, 39-51. [CrossRef]

25. Huang, T.; Wang, W.; Yuan, Y.; Huang, J.; Chen, X.; Zhang, J.; Kong, X.; Zhang, Y.; Wan, Z. Optimization of high-temperature proton exchange membrane fuel cell flow channel based on genetic algorithm. Energy Rep. 2021, 7, 1374-1384. [CrossRef]

26. Xia, L.; Xu, Q.; He, Q.; Ni, M.; Seng, M. Numerical study of high temperature proton exchange membrane fuel cell (HT-PEMFC) with a focus on rib design. Int. J. Hydrogen Energy 2021, 46, 21098-21111. [CrossRef]

27. Nishimura, A.; Kamiya, S.; Okado, T.; Sato, Y.; Hirota, M.; Kolhe, M.L. Heat and mass transfer analysis in single cell of PEFC using different PEM and GDL at higher temperature. Int. J. Hydrogen Energy 2019, 44, 29631-29640. [CrossRef]

28. Nishimura, A.; Yoshimura, M.; Mahadi, A.H.; Hirota, M.; Kolhe, M.L. Impact of operation condition on temperature distribution in single cell of polymer electrolyte fuel cell operated at higher temperature than usual. Mech. Eng. J. 2016, 3, 16-00304. [CrossRef]

29. Wong, C.Y.; Wong, W.Y.; Ramya, K.; Khalid, M.; Loh, K.S.; Daud, W.R.W.; Lim, K.L.; Walvekar, R.; Kadhum, A.A.H. Additives in proton exchange membranes for low- and high-temperature fuel cell applications: A review. Int. J. Hydrogen Energy 2019, 44, 6116-6135. [CrossRef]

30. Xing, L.; Das, P.K.; Song, X.; Mamlouk, M.; Scott, K. Numerical analysis of the optimum membrane/ionomer water content of PEMFCs: The interface of Nafion ionomer content and cathode relative humidity. Appl. Energy 2015, 138, 242-257. [CrossRef]

31. Salomov, U.R.; Chiavazzo, E.; Fasano, M.; Asinari, P. Pore- and macro-scale simulations of high temperature proton exchange fuel cells-HTPEMFC—And possible strategies for enhancing durability. Int. J. Hydrogen Energy 2017, 42, 26730-26743. [CrossRef] 
32. Jia, T.; Shen, S.; Zhao, J.; Jin, J.; Pan, B.; Duan, X.; Meng, C.; Che, Q. Ultrathin membranes formation via the layer by layer self-assembly of carbon nanotubes-based inorganics as high temperature proton exchange membranes. Int. J. Hydrogen Energy 2020, 45, 14517-14527. [CrossRef]

33. Fu, X.; Li, T.; Tang, L.; Deng, X.; Zhang, R.; Hu, S.; Zhao, F.; Li, X.; Liu, Q. Reticulated polyaniline nanowires as a cathode microporous layer for high-temperature PEMFCs. Int. J. Hydrogen Energy 2021, 46, 8802-8809. [CrossRef]

34. Quan, P.; Lai, M.C. Numerical study of water management in the air flow channel of a PEM fuel cell cathode. J. Power Sources 2007, 164, 222-237. [CrossRef]

35. Jiao, K.; Park, J.; Li, X. Experimental investigation on liquid water removal from the gas diffusion layer by reaction flow in PEM fuel cell. Appl. Energy 2010, 87, 2770-2777. [CrossRef]

36. Nishimura, A.; Yoshimura, M.; Kamiya, S.; Hirota, M.; Hu, E. Impact of relative humidity of supply gas on temperature distributions in single cell of polymer electrolyte fuel cell when operated at high temperature. J. Energy Power Eng. 2017, 11, 706-718. [CrossRef]

37. Mariani, M.; Latorrata, S.; Patrignani, S.; Gallo, S.P.; Dotelli, G. Characterization of novel graphene-based microporous layers for polymer electrolyte membrane fuel cells operating under low humidity and high temperature. Int. J. Hydrogen Energy 2020, 45, 7046-7058. [CrossRef]

38. Guo, H.; Wang, M.H.; Ye, F.; Ma, C.F. Experimental study of temperature distribution on anodic surface of MEA inside a PEMFC with parallel channels flow bed. Int. J. Hydrogen Energy 2012, 37, 13155-13160. [CrossRef]

39. Wang, H.Y.; Yang, W.J.; Kim, Y.B. Analyzing in-plane temperature distribution via a micro-temperature sensor in a unit polymer electrolyte membrane fuel cell. Appl. Energy 2017, 124, 148-155. [CrossRef]

40. Zhang, S.; Zhang, J.; Zhu, Z.; Liu, P.; Cao, F.; Chen, J.; He, Q.; Dou, M.; Nan, S.; Lu, S. Unusual influence of binder composition and phosphoric acid leaching on oxygen mass transport in catalyst layers of high-temperature proton exchange membrane fuel cells. J. Power Sources 2020, 473, 228616. [CrossRef]

41. Xu, Z.; Qiu, D.; Yi, P.; Peng, L.; Lai, X. Towards mass applications: A review on the challenges and developments in metallic bipolar plates for PEMFC. Prog. Nat. Sci. Mater. Int. 2020, 30, 815-824. [CrossRef]

42. Wu, S.; Yang, W.; Yan, H.; Zuo, X.; Cao, Z.; Li, H.; Shi, M.; Chen, H. A review of modified metal bipolar plates for proton exchange membrane fuel cells. Int. J. Hydrogen Energy 2021, 46, 8672-8701. [CrossRef]

43. Saadat, N.; Dhakal, H.N.; Tjong, J.; Jaffer, S.; Yang, W.; Sain, M. Recent advances and future perspectives of carbon materials for fuel cell. Renew. Sustain. Energy Rev. 2021, 138, 110535. [CrossRef]

44. New Energy and Industry Technology Development Organization (NEDO). Available online: https://www.nedo.go.jp/cotent/ 100642947 (accessed on 23 November 2021). (In Japanese) 